University of Nebraska - Lincoln

DigitalCommons@University of Nebraska - Lincoln

2013

\title{
Ground vibrations produced by surface and near-surface explosions
}

\author{
Donald G. Albert \\ U.S. Army ERDC Cold Regions Research and Engineering Laboratory, Donald.G.Albert@usace.army.mil \\ Shahram Taherzadeh \\ The Open University \\ Keith Attenborough \\ The Open University \\ Patrice Boulanger \\ The University of Hull \\ Stephen N. Decato \\ U.S. Army ERDC Cold Regions Research and Engineering Laboratory
}

Follow this and additional works at: https://digitalcommons.unl.edu/usarmyresearch

Albert, Donald G.; Taherzadeh, Shahram; Attenborough, Keith; Boulanger, Patrice; and Decato, Stephen N., "Ground vibrations produced by surface and near-surface explosions" (2013). US Army Research. 176. https://digitalcommons.unl.edu/usarmyresearch/176

This Article is brought to you for free and open access by the U.S. Department of Defense at DigitalCommons@University of Nebraska - Lincoln. It has been accepted for inclusion in US Army Research by an authorized administrator of DigitalCommons@University of Nebraska - Lincoln. 


\title{
Ground vibrations produced by surface and near-surface explosions
}

\author{
Donald G. Albert ${ }^{\mathrm{a}, *}$, Shahram Taherzadeh ${ }^{\mathrm{b}}$, Keith Attenborough ${ }^{\mathrm{b}}$, Patrice Boulanger ${ }^{\mathrm{c}, 1}$, \\ Stephen N. Decato ${ }^{a}$
}

${ }^{a}$ U.S. Army ERDC Cold Regions Research and Engineering Laboratory, 72 Lyme Road, Hanover, NH 03755-1290, USA

${ }^{\mathrm{b}}$ Faculty of Mathematics, Computing, and Technology, The Open University, Milton Keynes MK7 6AA, UK

${ }^{\mathrm{C}}$ Dept. of Engineering, The University of Hull, Cottingham Road, Hull HU6 7RX, UK

\section{A R T I C L E I N F O}

\section{Article history:}

Received 12 December 2007

Received in revised form 1 March 2013

Accepted 13 March 2013

Available online 7 June 2013

\section{Keywords:}

Acoustic-to-seismic coupling

Outdoor sound propagation

Ground vibration

Seismic wave propagation

Building damage criteria

\begin{abstract}
A B S T R A C T
Measurements of seismic signatures produced by airborne, near-surface detonations of explosive charges over a variety of ground types show two distinct ground vibration arrivals. In all cases, the earlier arrival (precursor), has a time of arrival consistent with a predominantly underground path and coupling of blast sound to the ground close to the source and is always much smaller than the later vibration, the time of arrival of which is consistent with coupling from the air blast arrival at the receiver. The ratio of the seismic particle velocity to the acoustic pressure at the surface for the air-coupled seismic wave is constant with respect to distance and maximum pressure at a given location, but varies from site to site, with values usually between 1 and $13 \mu \mathrm{m} \mathrm{s}^{-1} \mathrm{~Pa}^{-1}$. For the precursor seismic wave, a coupling coefficient of $0.16 \mu \mathrm{m} \mathrm{s}^{-1} \mathrm{~Pa}^{-1}$ was measured.

A numerical code enabling calculations of the fields due to an impulsive source above a layered poroelastic ground is described. Predictions of the air pressure spectrum above ground and the vertical and radial components of solid particle velocity near the ground surface are found to compare tolerably well with the measured spectra and waveforms of acoustic and seismic pulses at about $100 \mathrm{~m}$ range in seismically-hard and -soft soils and with a snow cover present. The predicted seismic responses in 'soft' soil confirm that the existence of a near-surface S-wave speed less than that in air is responsible for the observed 'ringing', i.e. a long low-frequency wavetrain associated with coupling to the dispersive Rayleigh wave. The predicted seismic pulses in the presence of the shallow snow cover explain the observed phenomenon whereby a high frequency ground vibration is modulated by a lower frequency layer resonance.

An empirical equation relating ground vibration from explosions to distance predicts that the commonly-used vibrational damage peak velocity criterion of 12 or $25 \mathrm{~mm} \mathrm{~s}^{-1}$ will be exceeded when the peak positive pressure exceeds $480 \mathrm{~Pa}(147.6 \mathrm{~dB})$ or $1 \mathrm{kPa}(154.0 \mathrm{~dB})$, respectively. Either of these levels is much higher than the current U.S. Army overpressure damage criterion of $159 \mathrm{~Pa}(138 \mathrm{~dB})$. Thus in most situations damage from blast overpressure will occur long before damaging levels of ground vibration are reached, so it is likely that civilian perceptions of vibration are produced by coupling from the airblast.
\end{abstract}

Published by Elsevier Ltd.

\section{Introduction}

As an acoustic wave propagates close to the ground, it continually interacts with the ground and induces ground vibrations. This process, known as acoustic-to-seismic coupling, is important in a variety of practical applications. For example, the performance of sensor systems using geophones to detect air or ground vehicles [1] can be greatly influenced by ground conditions [2]. Also, low frequency seismic stations can detect and provide information

\footnotetext{
* Corresponding author. Tel.: +1 6036464459.

E-mail address: Donald.G.Albert@usace.army.mil (D.G. Albert).

${ }^{1}$ Current address: La Peyre, 24210 Azerat, France.
}

about natural atmospheric phenomena including meteoroids [3] and thunder $[4,5]$ when recognized and correctly identified. Sonic booms and infrasound from aircraft, rockets, and space vehicle reentry have also been studied using seismic sensors [6-9]. The use of laser doppler vibrometers to measure acoustically-induced ground vibrations $[10,11]$ has been exploited to locate buried landmines remotely e.g. [12-14]. Acoustic-to-seismic coupling is sometimes also involved in civilian noise complaints [15] and possible building damage [16] caused by military training and other activities; the latter application is the major motivation for this study.

When an explosive charge is detonated above or on the surface of the ground, a pressure wave begins to propagate away from the charge location. As this pressure wave propagates over and 
interacts with the ground surface, it induces ground vibrations. This wave is shown as Path A in Fig. 1, with an acoustic-to-seismic coupling coefficient $\mathrm{C} 1$, and is called the air-coupled seismic wave in this paper. In addition to inducing ground vibration as the airblast propagates horizontally along the ground surface, the airblast also interacts with the ground directly beneath the source and produces waves that propagate mostly as seismic (ground) waves. These waves correspond to Path B in Fig. 1, with a coupling coefficient $\mathrm{C} 2$, and are termed precursor seismic waves in this paper. Because these waves are small compared to the air-coupled waves, they have not been extensively studied and they cannot be easily detected with acoustic measurements using continuous wave sources.

Air-induced ground vibration has been studied since at least the early 1950s. These early studies concentrated on the strong coupling that occurs when the phase velocities of the atmospheric acoustic wave matched the phase velocities of dispersed seismic surface waves at a particular frequency [17-19]. McDonald and Goforth [9] reported that the strongest seismic signals produced by sonic booms occurred when the air shock wave passed over the seismic sensors, but they also noticed a small seismic precursor when the ground velocity was higher than the air wave velocity. Clear examples of these precursor seismic waves were reported by Gupta and Hartenberger [20], and Kanamori et al. [8] also observed early seismic arrivals produced by a space shuttle. Birds have sometimes been observed to respond to these precursor seismic waves a few seconds before the arrival of a loud sonic boom [21]. Precursor seismic waves have also been observed in short range measurements using blank pistol shots as the acoustic source [22], and in long range measurements using large explosive charges [15,16,23,24].

A viscoelastic model of acoustic-to-seismic coupling [17,25] gives acceptable agreement with long range pulse measurements where seismic surface waves dominate the ground response, e.g. $[6,19,23]$. However, Bass et al. [26] reported on small scale measurements of acoustic-to-seismic coupling into soil using a loudspeaker emitting continuous waves as a source and found that the magnitude of the air-coupled seismic wave was much larger than expected from elastic wave theory; they suspected that the porous nature of the ground might explain the discrepancy.

The theory of acoustic plane wave interaction with a porous elastic layer over a porous elastic half space was derived by Sabatier et al. $[27,28]$ and good agreement with short-range measurements was obtained [28,29]. Sabatier and Raspet [16] extended the porous medium theory by integrating over frequency using an FFT to obtain the response of the ground to an acoustic pulse. Other frequency-domain treatments include Tooms et al. [30] and Madshus et al. [15]. Dong et al. [31] later developed a time

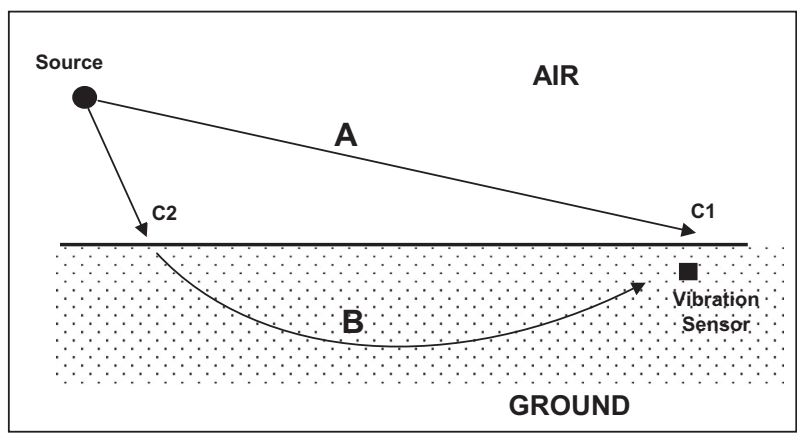

Fig. 1. Hypothetical propagation paths contributing to the ground vibration produced by an explosive source in the air or on the ground. Waves are postulated to propagate to a buried vibration sensor following an airborne path (A) and a predominantly subsurface or seismic path (B) domain finite difference solution for atmospheric pulses propagating over a porous medium.

To gain a better understanding of the ground vibration produced by near surface explosions, an extensive series of field measurements using relatively small explosive charges (compared to industrial mining activities) is presented and analyzed. The goal of this analysis is to determine the properties and types of waves produced and the effect of environmental conditions on these waves. An extension of the frequency-domain fast field approach [30] to calculate time domain waveforms is used to compare the measurements with theoretical predictions, validate a simple interpretation of the time-amplitude data, and provide a basis for examining any frequency dependence in the coupling process. In addition, conservative predictive relationships between the charge size, propagation distance, and maximum ground vibration are derived from the measurements and used to predict when cosmetic building damage might occur.

\section{Current empirical criteria for estimating cosmetic building damage}

In this section, previous measurements of shallow seismic attenuation are discussed and methods currently used by the US Department of Defense to estimate building damage are reviewed.

Both the precursor and air-coupled seismic waves are subject to amplitude decay from divergence of the wavefront (geometric spreading) and from material losses in the air or ground (absorption). Following the discussion in Coward et al. [32] the amplitude of a seismic wave as a function of distance can be written as

$A(R)=A_{0} R^{-\gamma} \exp (-\delta R)$

where the coefficient $\gamma$ is a geometric divergence (with a value of 0.5 for surface waves and 1.0 for body waves ([33], p. 221)), $\delta$ represents the loss from material absorption, and $A_{0}$ is the amplitude at the source. Amick [34] reviewed the geotechnical literature and reported published values of $\delta$ from 0.00037 to $0.024 \mathrm{~m}^{-1}$ $\left(0.012-0.08 \mathrm{ft}^{-1}\right)$ in peer reviewed publications. (Two unreviewed publications reported higher values up to $0.041 \mathrm{~m}^{-1}\left(0.134 \mathrm{ft}^{-1}\right)$ ).

For real (noisy) measurements at small values of $\delta R$, the material attenuation is difficult to determine, and, as will be shown below, the measurements in this paper do not show the exponential decay implied by Eq. (1), implying that those losses are small and can be neglected. In this case a more useful form of equation is

$A(R)=A_{0} R^{-\alpha}$

where $\alpha$ is an attenuation coefficient that includes all losses including geometric divergence, boundary effects, and material losses. Amick [34] reported published values of $\alpha$ from seismic measurements from 0.8 to 1.7. Eq. (2) can be written to show the dependence of explosive output on the cube root of the charge weight, $W[35]$

$A(R)=B_{0}\left(R / W^{1 / 3}\right)^{-\alpha}$

Recently, activities including soldier artillery training and demilitarization (destruction of old weapon stocks) have been subjected to structural damage claims from civilian populations surrounding military facilities. The U.S. Department of Defense currently uses a simple procedure based on an empirical relation to assess damage claims that attribute ground motion to military activities [36]. In this procedure, empirical equations formulated by the mining industry and regulatory agencies $[37,38]$ are used to estimate the maximum level of ground vibration caused by the military activity. A claim is viewed to have merit if the estimated ground motion has a value of $25.4 \mathrm{~mm} \mathrm{~s}^{-1}\left(1.0\right.$ in s $\left.\mathrm{s}^{-1}\right)$ or larger based on these empirical equations. (Some mining 
regulations use a more stringent threshold value of $12 \mathrm{~mm} \mathrm{~s}^{-1}$ or 0.5 in $\mathrm{s}^{-1}$ ). These vibration levels are based on the cosmetic damage observed on US wood frame houses [38]. However, mining industry blasting significantly differs from Army activities, especially in the use of very large explosive charge sizes (typically thousands of kilograms of TNT) spread over a relatively large area (to break the most rock). Thus the empirical equations currently in use may not be accurate when applied to military activities, which usually involve point sources much smaller in explosive size. In addition, many military activities including artillery training and demolitions work use airborne explosives rather than the buried charges most often used in mining. Wright [36] states that the airblast damage criterion adopted by the U.S. Department of Defense is $159 \mathrm{~Pa}$ (or $138 \mathrm{~dB}$ re $20 \mu \mathrm{Pa}$ ). If either the maximum particle velocity or the maximum air pressure damage criteria are met, the claim is then further evaluated to see if damage compensation is warranted.

To predict ground motion, Wright [36] presents two equations in the form

$V_{\max }=A_{0}\left(R / W^{1 / 3}\right)^{-\alpha}$

where $V_{\max }$ is the maximum particle velocity $\left(\mathrm{m} \mathrm{s}^{-1}\right) ; A_{0}$ is a constant coefficient; $R$ is the distance from explosion $(\mathrm{m}) ; W^{1 / 3}$ is the cube root of TNT equivalent explosive charge weight $\left(\mathrm{kg}^{1 / 3}\right)$, and $\alpha$ is the an attenuation coefficient that includes divergence and material losses.

Wright cites Siskind et al. [38] and Johnson et al. [39] as sources for the values of the coefficients $A_{0}$ and $\alpha$ for surface explosions and for buried explosions, respectively. Unfortunately, there appear to be typographical errors in the coefficients listed by Wright [36] so the equations from that report have not been used here. Instead, equations presented by Dowding [37] based on measured data from surface mining are used. The first relationship, appearing in Dowding's Figure 4-4, is reproduced from a study by Ambrayseys and Hendron [40] and was developed from surface mining explosions ranging in size from 14 to $145,000 \mathrm{~kg}$. In addition, Dowding [37] presents equations based on his own measurements of buried mining explosions for charge sizes from 1 to $8900 \mathrm{~kg}$. By combining terms and dropping the dependence on soil or rock density, the empirical equations in SI units are

$V_{\max }=81.91\left(R / W^{1 / 3}\right)^{-1.6}$

for a surface explosion, and

$V_{\max }=1.78\left(R / W^{1 / 3}\right)^{-1.46}$

for a buried explosion.In these equations, the distance $R$ is to be given in $\mathrm{m}$, the charge weight $W$ in $\mathrm{kg}$, and the maximum particle velocity is in $\mathrm{m} \mathrm{s}^{-1}$. From the leading coefficients the predicted maximum particle velocities from Eqs. (5) and (6) can be seen to differ by about a factor of 20 .

\section{Measurement methods}

Experimental measurements of the acoustic and seismic signatures produced by near-surface explosions were conducted at seven different locations having a variety of ground and vegetative conditions for propagation distances from 8 to $565 \mathrm{~m}$. The measurements were sponsored and conducted for projects with different goals from the analysis presented here, so the parameters of the tests (including charge size, charge height, and propagation distance) vary somewhat from one measurement location to another. Table 1 lists the details of the different measurement parameters.

For each experiment, an array of sensors was installed at the ground surface at selected distances from the source locations. At each sensor location, either a solid state PCB pressure sensor or a $1 / 4$ in. diameter Bruel and Kjaer microphone was used to record the air blast wave at the ground surface level. The solid state sensors were capable of measuring higher pressure levels and so were generally usually used for propagation distances of $100 \mathrm{~m}$ and less, while the microphones were used at greater distances. These pressure sensors were calibrated in the field using a Trig-Tek Model $402 \mathrm{H}$ calibrator capable of producing a high pressure signal at 62.5 and $125 \mathrm{~Hz}$. In addition, Mark Products L-15 geophones with a resonant frequency of $4.5 \mathrm{~Hz}$ were used to record the ground vibrations. The geophones included one vertical component, and either one (radial) or two (radial and transverse) horizontal components. These geophones produce a voltage output that is proportional to the ground particle velocity. The geophones were not calibrated in situ; however previous calibration tests showed them to have a flat response from $4.5 \mathrm{~Hz}$ to above $500 \mathrm{~Hz}$ ([41] Fig. 12, page 11). The number of instrumented sensor locations, propagation distances, charge sizes and source heights varied from one test to another and are listed in Table 1.

For most of the measurements, a Geometrics NZ multichannel digital seismograph recorded the time series output of the sensors using a sampling rate of $8 \mathrm{kHz}$ per channel. This recording system has 24 bit digitizers giving the measurements a very wide dynamic range. A single measurement (Test 3 discussed below) used the same recording system but at a sampling rate of $32 \mathrm{kHz}$, and the earliest measurement (Test 1) used a different recorder (a Bison Model 9048 with 16 bits plus 4 gain bits) at a sampling rate of $5 \mathrm{kHz}$. The recordings were started using either a signal from the blasting cap firing box or by using a break wire placed within the C4 charge itself.

\subsection{C4 Charge heights}

Because of site restrictions, only three of the tests included C4 charges placed at the ground surface (see Table 1). In agreement with Press and Ewing [19], the measured pressures and ground vibrations produced by ground shots were similar to those for air shots in the same location, so the surface and near-surface measurements have been combined in the analysis below. Since little difference was found in the measurements for various charge

Table 1

Test environments, charge sizes, and propagation distances.

\begin{tabular}{|c|c|c|c|c|c|c|}
\hline Test \# & Type & Location (State) & Charge heights (m) & Charge size range (blocks of C4) & Charge size $(\mathrm{kg})$ & Distance range $(\mathrm{m})$ \\
\hline 1 & Concrete & MD & 1.5 & 1 & 0.57 & $8-91$ \\
\hline 2 & Soil & MD & 1.5 & $1-128$ & $0.57,5.7,9.1,18.2,72.7$ & $100-240$ \\
\hline 3 & Soil and Gravel pile & MD & $1.0,1.5,3.0$ & 1 & 0.57 & $60-405$ \\
\hline 4 & Tropical vegetation & FL & $0.0,1.5$ & $0.5-8$ & $0.28,0.57,2.3,4.6$ & $30-100$ \\
\hline 5 & Forest & $\mathrm{TX}$ & $0.3,1.2,1.9,3.0,3.8$ & $1-4$ & $0.57,2.3$ & $30-565$ \\
\hline 6 & Snow/frozen ground & MN & $0.0,1.5$ & $0.5-8$ & $0.28,0.57,2.3,4.6$ & $30-100$ \\
\hline 7 & Deep Snow & NY & $0.0,1.5$ & $0.5-8$ & $0.28,0.57,2.3,4.6$ & 60,150 \\
\hline
\end{tabular}


heights above the ground surface $(0.3 \mathrm{~m}$ to $3.8 \mathrm{~m}$, with most airborne charges at $1.5 \mathrm{~m}$ ), those measurements are also analyzed together for each location.

\section{Experimental site descriptions}

A brief description of each measurement site is provided in this section. For the relatively short propagation distances and low frequencies employed in these experiments, the ground conditions were the major environmental factor and meteorological effects were secondary. For all of the measurements the source and receiver positions were always line-of-sight over relatively flat ground, and located as far from reflecting obstacles as possible. Any such reflections were easily seen in the recorded time series and eliminated from the analysis.

\subsection{Test 1 - propagation over concrete}

This experiment [42] was conducted at the Aberdeen Test Center, Maryland in June 2001 as part of the SYDET (a U.S Army sensor) development project. The test was conducted over a $90 \times 90 \mathrm{~m}$ flat concrete pad located in the center of a $600 \times 600 \mathrm{~m}$ open field. A large concrete wall ( $7 \mathrm{~m}$ tall, $14 \mathrm{~m}$ wide, and $2 \mathrm{~m}$ thick) was located at one edge of the pad along with smaller vertical concrete targets approximately $3 \mathrm{~m}$ by $4 \mathrm{~m}$ tall along another edge of the pad. Reflections from these objects are visible in the time series waveforms but separated in time from the main arrivals and have no effect in the analysis. Sensors (microphones and geophones) were arranged in lines parallel and perpendicular to the large wall, and the geophones were drilled and cemented into place. Single blocks of C4 $(0.57 \mathrm{~kg})$ were detonated and the resulting signatures were measured using a digital seismograph. Charges of C4 explosive were suspended $1.5 \mathrm{~m}$ above the concrete pad and fired at various locations around the concrete pad, providing propagation distances ranging from $10 \mathrm{~m}$ to $93 \mathrm{~m}$.

\subsection{Test 2 - propagation over soil with light vegetation}

This experiment was conducted at the Aberdeen Test Center, Maryland in September 2004 as part of the SYDET development project. The test was conducted in a large field approximately $500 \times 500 \mathrm{~m}$ in extent covered with sandy soil and light vegetation consisting of grass, weeds, and a few scattered small trees. For this test various charge sizes of $\mathrm{C} 4$, ranging from 1 to 128 blocks (0.57$73 \mathrm{~kg}$ ) were detonated at a height of $1.5 \mathrm{~m}$ above ground level and the resulting signatures were measured using a digital seismograph for propagation distances of 10-240 m. Geophones were installed at four distances $100,120,180$, and $240 \mathrm{~m}$ from the source location. Geophones were not installed at distances less than $100 \mathrm{~m}$ from the source since they would have been overdriven by the larger charge sizes at closer distances.

\subsection{Test 3 - propagation over soil with light vegetation, near or over a gravel pile}

This experiment [43] was conducted at the Aberdeen Test Center, Maryland in June 2005 as part of a U.S Army Range Management project to determine whether a gravel pile could reduce the noise produced by artillery fire and ease civilian noise complaints. The test was conducted near the center of a large field $(4 \mathrm{~km} \times 1 \mathrm{~km})$ with light vegetation consisting of grass and weeds. A $15 \mathrm{~m} \times 15 \mathrm{~m} \times 1.5 \mathrm{~m}$ tall coarse gravel pile was constructed in the field and used as part of these tests. All of the measurements were made using single blocks of $\mathrm{C} 4$ as the source. For some of the measurements the explosives were detonated to the side of the gravel pile where all of the propagation occurred over undisturbed soil, while for other measurements the charge was detonated above or behind the gravel pile. The source height was varied from 1 to $3 \mathrm{~m}$ above the gravel or soil surface. Sensor locations from 60 to $405 \mathrm{~m}$ from the source are used in this analysis. Because there was very little difference in the measurement results from the various source locations for propagation distances of $100 \mathrm{~m}$ or greater, all of the measurements from the various source locations have been combined for this analysis.

\subsection{Test 4 - propagation through heavy tropical vegetation}

This experiment was conducted at the Eglin Air Force Base, Florida in August 2002 as part of the SYDET development project. The test was conducted in an area of very thick vegetation that limited the visibility to less than $30 \mathrm{~m}$ in most locations. There was an extensive amount of vegetative debris on the ground. The vegetated area was over $100 \mathrm{~m}$ in width and more than $150 \mathrm{~m}$ long (further investigation was discouraged by swarms of bugs!) For this test various charge sizes of $\mathrm{C} 4$, ranging from 0.5 to 8 blocks $(0.28-4.5 \mathrm{~kg})$ were detonated on the ground and also at a height of $1.5 \mathrm{~m}$ above ground level and the resulting signatures were measured for propagation distances between 30 and $100 \mathrm{~m}$.

\subsection{Test 5 - propagation through a conifer forest}

This experiment [44] was conducted at the Lone Star Army Ammunition Plant, Texas in July 2002 as part of a U.S. Army Range Management project to determine the effect of a forest on acoustic pulse propagation. The measurements were conducted at a demolition range greater than $700 \times 400 \mathrm{~m}$, with about one-third of the area in a mature forest. The ground was relatively flat except for a small berm less than 5 -m-high, located $100 \mathrm{~m}$ from the nearest sensor, where the recording equipment was located during the measurements. Five sensor stations were installed in the forest starting $30 \mathrm{~m}$ from the forest edge and spaced $30 \mathrm{~m}$ apart. There was a thick layer of pine needles on the ground at the sensor locations. Two charge sizes of C4, 1 and 4 blocks ( 0.57 and $2.3 \mathrm{~kg}$ ), were detonated at various heights ranging from 0.3 to $3.8 \mathrm{~m}$ above ground level and the resulting signatures were measured using a digital seismograph for propagation distances of 30 to $565 \mathrm{~m}$. Four different source locations were used. For two of the source locations the propagation path was entirely in the forest (with propagation distances of $30-281 \mathrm{~m}$ ) while for the other two source locations some of the corresponding paths were outside of the forest. In the latter cases, the propagation distances over open ground were $61 \mathrm{~m}$ and $415 \mathrm{~m}$, depending on the source location, followed by between 30 and $150 \mathrm{~m}$ of propagation through the forest to reach the various sensor locations. For the analysis presented here all of the source locations and source heights have been combined.

\subsection{Test 6 - propagation at a site with a thin low density snow cover} over frozen ground

This experiment [45] was conducted at Camp Ripley, Minnesota in March 2002 as part of the SYDET development project. These measurements were conducted in a demolition area about $200 \times 200 \mathrm{~m}$ in size, free of vegetation but with somewhat rough ground with high spatial variations on the order of $30-50 \mathrm{~cm}$ in height. A very low density and low strength snow cover was present at the site during the tests, and the geophones were drilled into the frozen soil because the snow cover was not strong enough to support them. Thus while a snow cover was present and affected the acoustic wave propagation, the ground motion that was measured was actually that of the frozen soil, not that of the thin, weak, overlying snow layer. The snow cover ranged from 10 to $15 \mathrm{~cm}$ in 
thickness and had an extremely low density of $60-90 \mathrm{~kg} \mathrm{~m}^{-3}$ (compared to a density of $1000 \mathrm{~kg} \mathrm{~m}^{-3}$ for water), with a thin crust at some locations with a density of $330 \mathrm{~kg} \mathrm{~m}^{-3}$. Snow permeability measurements were also conducted on small samples using a flow rig, yielding values of $35-40 \times 10^{-10} \mathrm{~m}^{-2}$. For this test various charge sizes of $C 4$, ranging from 0.5 to 8 blocks $(0.28-4.5 \mathrm{~kg})$ were detonated on the surface and at a height of $1.5 \mathrm{~m}$ above ground level and the resulting signatures were measured for propagation distances between 30 and $100 \mathrm{~m}$.

\section{Experimental results}

Observations and results of the measurements are presented in this section. The types of waves are identified and their characteristics are discussed, followed by a discussion of the propagation parameters determined from the measurements, including maximum amplitudes, coupling coefficients, and attenuation rates for the waves.

\subsection{Waveform observations}

Examples of the time series recordings and their properties are presented in this subsection. Fig. 2 shows a typical example of the time series waveforms recorded after the detonation of a single block of $\mathrm{C} 4$ at a height of $1.5 \mathrm{~m}$ above a concrete pad. In this figure, the sensors were located $90 \mathrm{~m}$ from the source. Because concrete is a material that has a very high acoustic impedance, it also has a high reflection coefficient and for this reason the maximum acoustic pressures for a given distance and explosive charge size are expected to be higher over concrete than for any other ground condition.

In Fig. 2 the main acoustic or blast wave can be seen arriving at all of the sensors about $0.25 \mathrm{~s}$ after the detonation, corresponding to a propagation velocity of $360 \mathrm{~m} \mathrm{~s}^{-1}$. This wave travels through the atmosphere and couples into the ground near the sensors corresponding to Path $A$ in Fig. 1 . It is identified as the air wave (for the acoustic component) or air-coupled seismic wave (for the
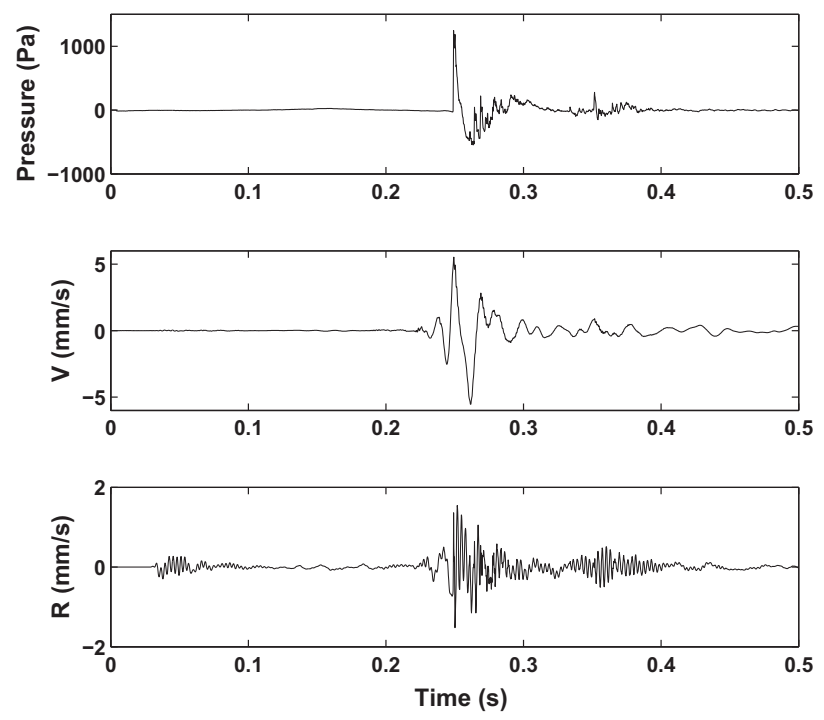

Fig. 2. Waveforms produced by the detonation of $0.57 \mathrm{~kg}$ of $\mathrm{C} 4$ at a height of $1.5 \mathrm{~m}$ above a concrete pad (Test 1). The sensors, a pressure sensor at the surface (top), vertical component geophone (center), and radial component geophone (bottom), were located $90 \mathrm{~m}$ from the explosive charge. The largest arrival on each sensor at about $0.25 \mathrm{~s}$ is the acoustic arrival (Path A in Fig. 1), with peak amplitudes of $1.2 \mathrm{kPa}, 5.5 \mathrm{~mm} / \mathrm{s}$, and $1.5 \mathrm{~mm} / \mathrm{s}$ respectively. A later arrival at about $0.35 \mathrm{~s}$ is the acoustic reflection from a wall located near the site. The precursor seismic arrival at $0.05 \mathrm{~s}$ is visible on the radial sensor. ground response). The wave speed of $360 \mathrm{~m} \mathrm{~s}^{-1}$ is higher than the expected acoustic wave speed of about $342 \mathrm{~m} \mathrm{~s}^{-1}$ because of nonlinear effects caused by the large amplitude near the source. In this case the ground vibration actually starts about $0.03 \mathrm{~s}$ before the acoustic arrival, but the maximum ground vibration is coincident with the acoustic arrival. The ground and air arrivals were usually simultaneous, but when the ground was very rigid with high seismic velocities, as in this case, the seismic wave was often observed to arrive slightly earlier than the air wave. The air wave with a maximum pressure of about $1.2 \mathrm{kPa}$ induces maximum seismic amplitudes of 5.5 and $1.5 \mathrm{~mm} / \mathrm{s}$ for the vertical and radial components, respectively. The later arrival visible at about $0.35 \mathrm{~s}$ is a reflection of the blast wave from a nearby obstacle.

A very early wave arrival with maximum amplitude of about $0.3 \mathrm{~mm} \mathrm{~s}^{-1}$ is also visible on the horizontal geophone at about $0.035 \mathrm{~s}$ in Fig. 2. The arrival time implies a propagation velocity of $2900 \mathrm{~m} \mathrm{~s}^{-1}$, so this wave must couple into the ground near the source and travel most of the way to the sensors through the high-velocity subsurface material; the wave could only travel a distance of $13 \mathrm{~m}$ through the air during this time interval. The velocity estimated from the arrival time agrees with the nominal compressional wave velocity of $2950 \mathrm{~m} \mathrm{~s}^{-1}$ for concrete. Because of the early arrival time, this wave is identified as the precursor seismic wave which is considered to travel along Path B in Fig. 1. A corresponding arrival was observed in all of the tests reported in this study. The precursor seismic arrival is also present on the vertical component with maximum amplitude of $0.044 \mathrm{~mm} \mathrm{~s}^{-1}$ but is not visible in Fig. 2 at the selected plot scale.

In Fig. 3 the same measurement over concrete is shown, but at a much higher amplification and for an expanded time scale so that only the time before the air wave arrival is visible. Only noise is present on the acoustic pressure sensor, but clear seismic arrivals are visible on the vertical and horizontal geophones with maximum amplitudes of 44 and $300 \mu \mathrm{m} \mathrm{s}^{-1}$ respectively, i.e. much smaller than those for the air-coupled seismic wave in the previous figure. These seismic waveforms are complex because the ground response from a point force includes a number of different types of waves [33]. The initial arrival at $35 \mathrm{~ms}$ is probably a compressional body wave or a longitudinal plate wave traveling through
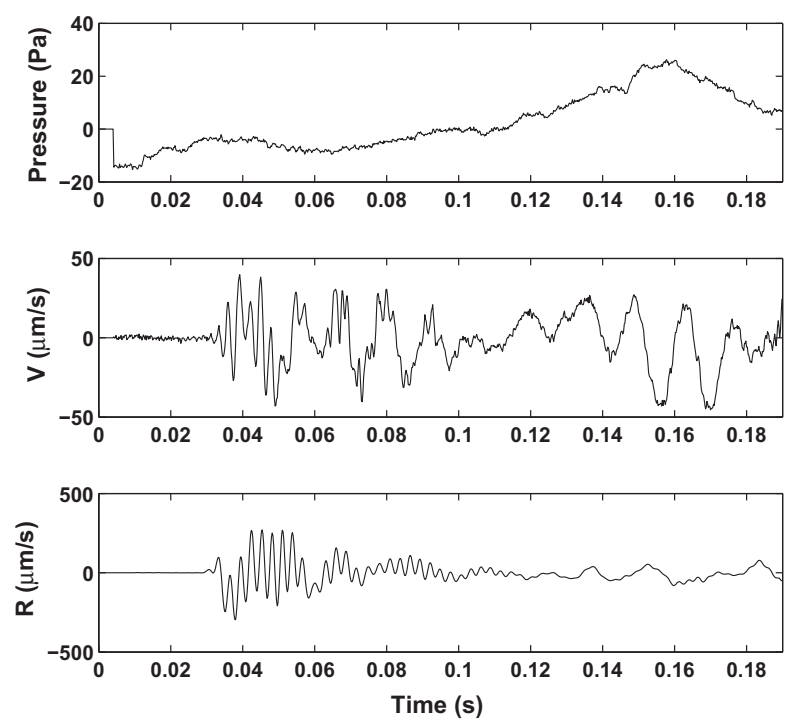

Fig. 3. This Figure shows the same data as Fig. 2 for propagation above a concrete pad, but for an earlier time window and a higher amplification. This time window shows the precursor seismic arrival on the seismic sensors, corresponding to Path B of Fig. 1, while the pressure sensor shows only noise. The peak amplitudes are 44 and $300 \mu \mathrm{m} / \mathrm{s}$ for the vertical and radial components, respectively. 

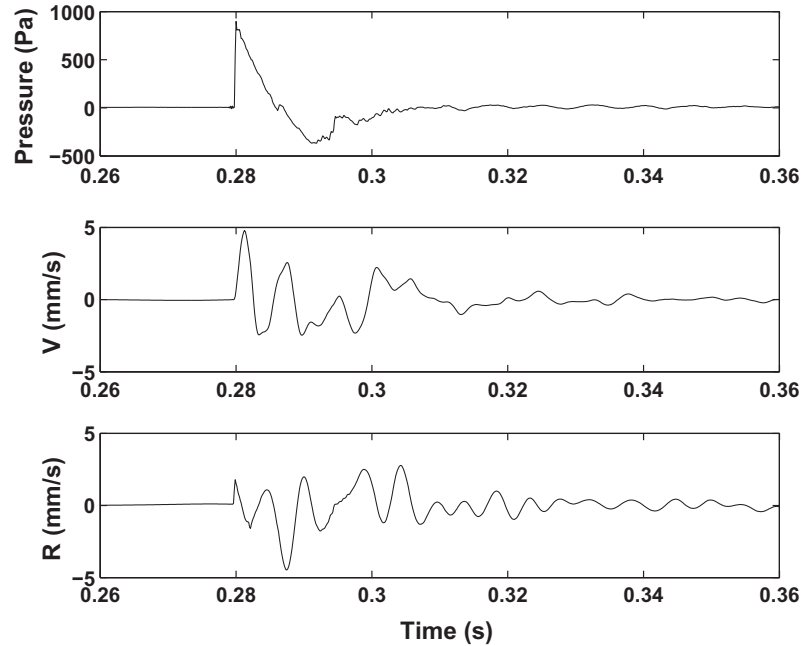

Fig. 4. Waveforms recorded during Test 2 after $100 \mathrm{~m}$ of propagation for the atmospheric arrival produced by the detonation of $0.57 \mathrm{~kg}$ of $\mathrm{C} 4$ at a height of $1.5 \mathrm{~m}$ above a hard soil i.e. with $V_{s}>c$. The peak amplitudes were $900 \mathrm{~Pa}, 4.8 \mathrm{~mm} / \mathrm{s}$, and $4.5 \mathrm{~mm} / \mathrm{s}$ for the pressure (top), vertical component geophone (center), and radial component geophone (bottom). In these and other data from the same experiment, the seismic signature durations are about the same as those of the acoustic pressure waves. (Contrast with a soft soil, in Fig. 5.) Peak frequency for both geophones is $175 \mathrm{~Hz}$, for pressure sensor is about $33 \mathrm{~Hz}$.

the concrete slab. Immediately after the initial arrival, high frequency oscillations at about $350 \mathrm{~Hz}$ are visible. There is also a low frequency component with a frequency of about $70 \mathrm{~Hz}$. This wave train is composed of various body wave and surface wave arrivals. Because of the slower propagation velocity, the arrivals after $100 \mathrm{~ms}$ are likely to be those that travel through or interact with the soil beneath the concrete slab. These seismic waves all may be considered to travel along the simplified propagation path B shown in Fig. 1.

The next three Figures contrast the measured responses in different ground conditions for nearly identical propagation geometry. Each shows the signatures produced by the detonation of a $0.57 \mathrm{~kg}$ charge of $\mathrm{C} 4$ at a height of $1.5 \mathrm{~m}$ above the ground measured after a propagation distance of $100-120 \mathrm{~m}$. Fig. 4 shows the waveforms recorded for a "hard" soil with some light grassy vegetation (Test 2 ). The Figure shows that the air-coupled seismic component motions induced by the air wave arrival are about $30 \mathrm{~ms}$ in duration, about as long as the waveform duration for the pressure sensor. The maximum amplitudes of both seismic components are nearly equal, and the maximum seismic frequency is about $175 \mathrm{~Hz}$. A soil may be considered "hard" when both the seismic compressional $\left(V_{p}\right)$ and shear $\left(V_{s}\right)$ velocities are greater than the (nonlinear) atmospheric acoustic velocity $(c)$ of about $357 \mathrm{~m} / \mathrm{s} ; V_{p}>V_{s}>c$. Such a situation appears to be the case with this soil because of the high wave speeds indicated by the early arrivals and from the modeling described later.

Fig. 5 shows data recorded at a site with a softer soil (Test 3 ). The seismic responses are very different from the appearance of the 'hard' soil measurements in Fig. 4, with a long, low-frequency wave train generated after the air wave arrival. While the 30 -mslong acoustic waveform is similar to the previous example (but more rounded, indicating higher ground attenuation for this soil), the seismic responses are monochromatic with durations over $80 \mathrm{~ms}$ long, and are phase shifted with respect to each other. These properties identify the arrivals as air-coupled Rayleigh waves. All of the sensors exhibit a maximum frequency of about $50 \mathrm{~Hz}$, and the coupling occurs because the acoustic velocity and Rayleigh wave velocity are identical at this frequency [19]. These properties
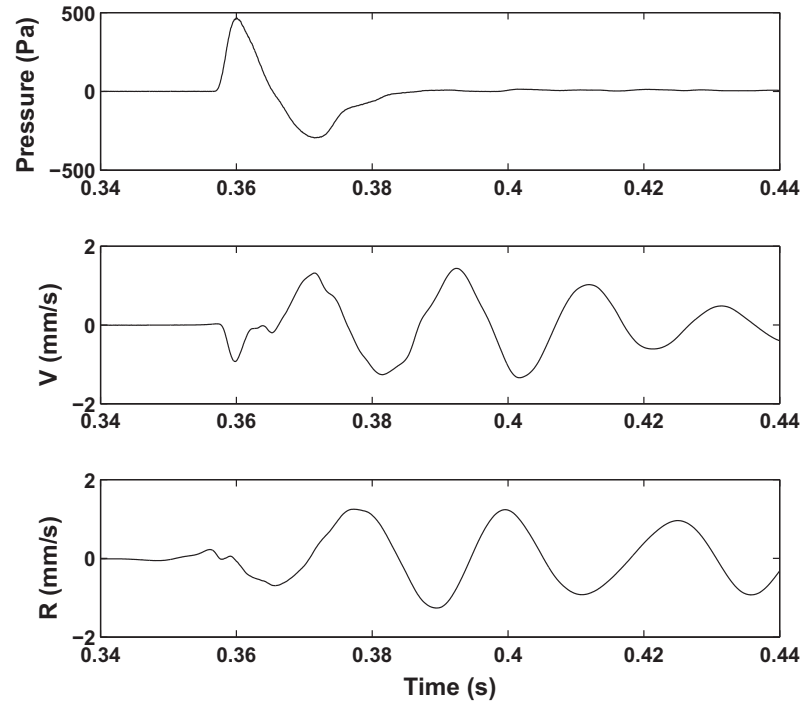

Fig. 5. Waveforms recorded during Test 3 after $120 \mathrm{~m}$ of propagation for the atmospheric arrival produced by the detonation of $0.57 \mathrm{~kg}$ of $\mathrm{C} 4$ at a height of $1.5 \mathrm{~m}$ above a soft soil i.e. with $V_{s}<c$. The peak amplitudes were $470 \mathrm{~Pa}, 1.4 \mathrm{~mm} / \mathrm{s}$, and $1.3 \mathrm{~mm} / \mathrm{s}$ for the pressure (top), vertical component geophone (center), and radial component geophone (bottom). In these and other data from the same experiment the seismic signature durations are much longer than the acoustic pressure waveforms. The waveform shape and phase relationships are typical of an aircoupled Rayleigh wave. (Contrast with the hard soil in Fig. 5.) Peak frequency for both geophones and the pressure sensor is about $50 \mathrm{~Hz}$.

are controlled by the shallow soil stratigraphy and seismic velocity structure. For both of the soil examples the main seismic response starts at the same time as the air wave arrival, not earlier as was observed for the measurements over the concrete pad. In this soil it is likely that $V_{p}>c>V_{s}$ as would be required for Rayleigh wave coupling and as confirmed by the modeling described later.

Fig. 6 shows the measured responses at $100 \mathrm{~m}$ when a thin, very weak snow cover was present. In this case, the snow was too weak
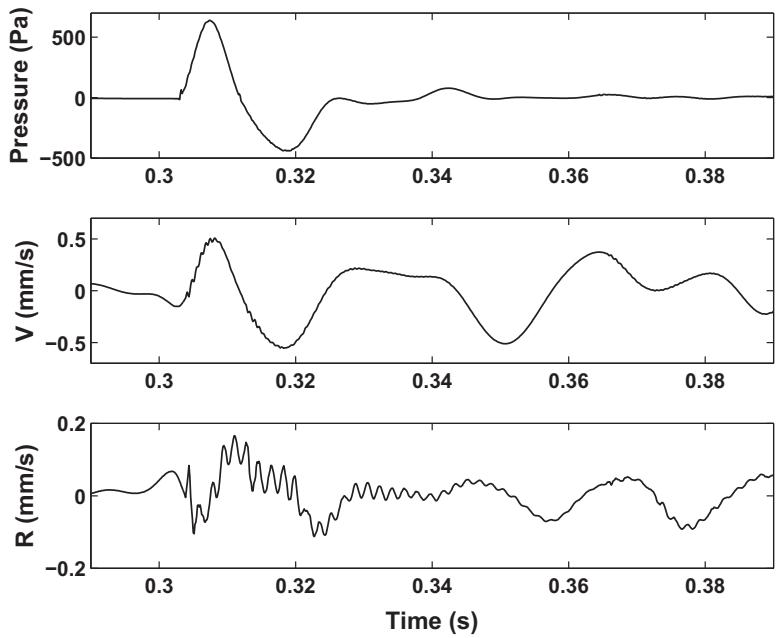

Fig. 6. Waveforms recorded during Test 6 after $100 \mathrm{~m}$ of propagation for the atmospheric arrival produced by the detonation of $0.57 \mathrm{~kg}$ of C4 at a height of $1.5 \mathrm{~m}$ above a low density snow cover over frozen ground. The peak amplitudes were $640 \mathrm{~Pa}, 0.81 \mathrm{~mm} / \mathrm{s}$, and $0.176 \mathrm{~mm} / \mathrm{s}$ for the pressure (top), vertical component geophone (center), and radial component geophone (bottom). In these and other data from the same experiment, the seismic signature durations are much longer than the acoustic pressure waveforms. The waveform shape and phase relationships are typical of an air-coupled Rayleigh wave. The radial geophone signal is a high frequency resonance modulated by a low frequency wave similar to the vertical component geophone. 
to support the geophones, so they were installed in the frozen soil beneath the snow. The pressure waveform is distorted by the interaction with the porous snow cover, showing a rounded appearance with the high frequencies attenuated [46]. The air-coupled seismic responses have a similar low-frequency appearance, but are longer in duration than the acoustic pulse. In addition, the radial component has a strong high frequency (about $550 \mathrm{~Hz}$ ) superimposed on the low frequency response. This high frequency component is often but not always observed in snow cover measurements.

Fig. 7 shows the precursor seismic arrivals for the hard soil (Test 2, same measurement as in Fig. 4). The wave amplitudes are 29 and $7.7 \mu \mathrm{m} / \mathrm{s}$ for the vertical and radial components, respectively, more than two orders of magnitude lower than the maximum amplitudes of the airblast-induced vibration shown in Fig. 4. The vertical and horizontal components are similar to each other, with a phase shift present, and show a long wave train typical to the body and
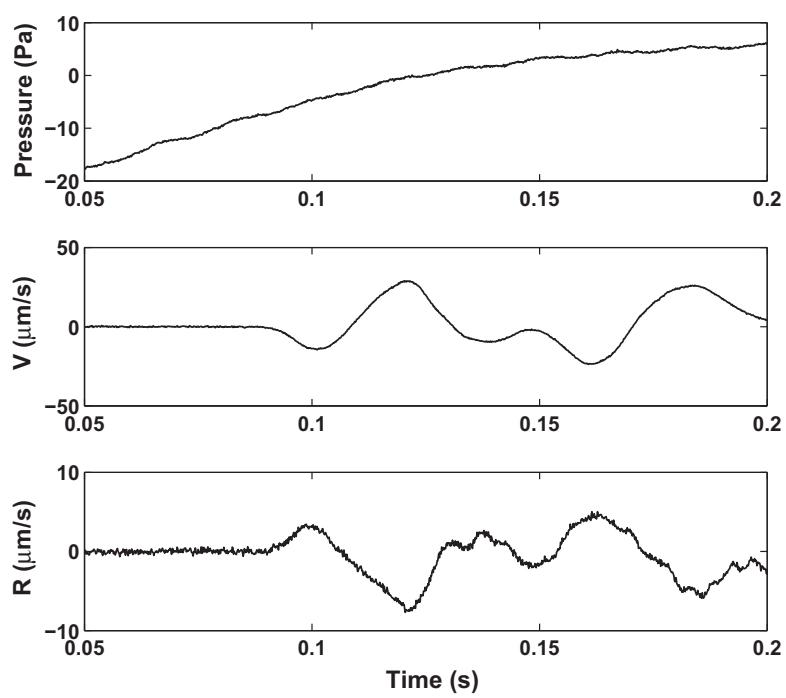

Fig. 7. Precursor seismic arrival waveforms observed during Test 2 produced by the detonation of $0.57 \mathrm{~kg}$ of $\mathrm{C} 4$ at a height of $1.5 \mathrm{~m}$ above a hard soil $100 \mathrm{~m}$ from the sensors. This figure shows the same data as Fig. 4, but for an earlier time window and a higher amplification. Early seismic arrivals are visible on the seismic sensors, corresponding to Path B of Fig. 1, while the pressure sensor shows only noise. The peak amplitudes are 29 and $7.7 \mu \mathrm{m} / \mathrm{s}$ for the vertical and radial components, respectively, more than two orders of magnitude lower than the peak amplitudes of the airblast-induced vibration shown in Fig. 4. The peak frequency of these seismic waves is about $20 \mathrm{~Hz}$. surface wave response expected from a point force at a layered ground surface. The maximum frequency of these seismic waves is about $20 \mathrm{~Hz}$. Precursor seismic arrivals like these were observed at every test location, and they were always much smaller than the air-wave-induced later arrivals.

To examine the repeatability of the explosion source, the waveforms produced by repeated shots at a given location are very similar as shown in Fig. 8, where 4 individual shots over two days are compared for distances of 10 and $30 \mathrm{~m}$ from the explosion. Fig. 8 shows that these waveforms are very similar to each other. For the recordings at $10 \mathrm{~m}$ distance, the mean peak amplitude was $26.6 \mathrm{kPa}$ with a standard deviation of $3.3 \mathrm{kPa}$, and the mean arrival time was $23.15 \mathrm{~ms}$ with a standard deviation of $0.45 \mathrm{~ms}$. At $30 \mathrm{~m}$ distance the peak amplitude values were 4.5 and $0.55 \mathrm{kPa}, 79.9$ and $0.88 \mathrm{~ms}$. The variation in peak pressure for a distance of $10 \mathrm{~m}$ was less than $14 \%$. This variation could be caused by differences in explosive charge output, undersampling of the waveform (relatively slow sampling rates of $8 \mathrm{kHz}$ were used for most tests, and the actual peak could have been underestimated), and differences in environmental conditions. As shown in the figure, the detonations recorded on the same day agree closely with each other but differ slightly with the recordings made on a different day. There were periods of light rain during the tests so it is likely that the soil moisture as well as the atmospheric conditions were different on the two test days.

\subsection{Maximum amplitude measurements}

In this section the measured maximum amplitudes are analyzed to determine the relations between the maximum airblast pressure, induced ground vibration, propagation distance, charge size, and ground type. In addition, the coupling coefficients C1 and $\mathrm{C} 2$ for the propagation paths shown in Fig. 1 will be determined along with attenuation rates.

\subsubsection{Maximum amplitude results for individual tests over different ground conditions}

Measured data recorded at each of the test sites were individually analyzed to determine the properties of the various ground conditions. The maximum amplitudes measured for Test 2, propagation over a relatively hard soil, are used as an example in this section because this test had the greatest range of charge sizes and relatively long propagation distances. These measurements were obtained for a wide range of charge sizes from 0.57 to $73 \mathrm{~kg}$. The measurements were scaled to a charge size of $1 \mathrm{~kg}$ of
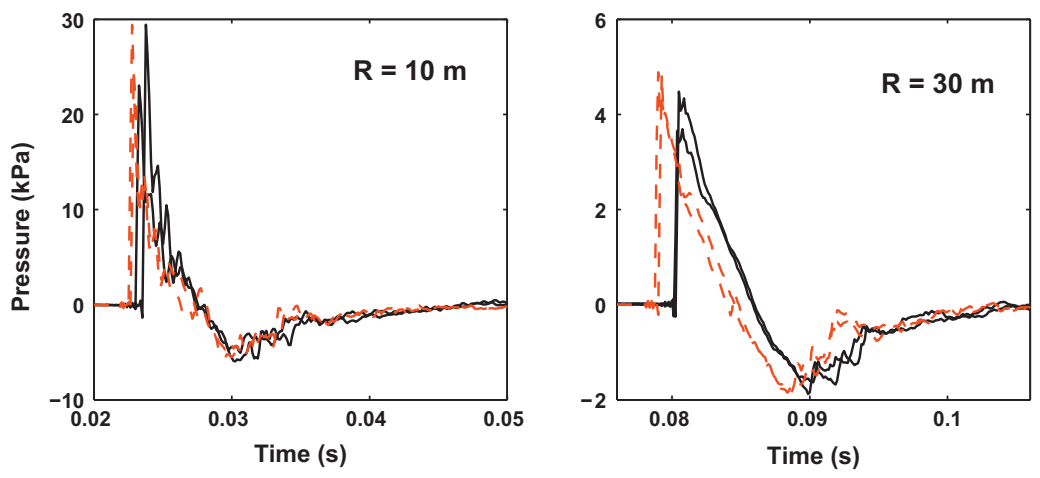

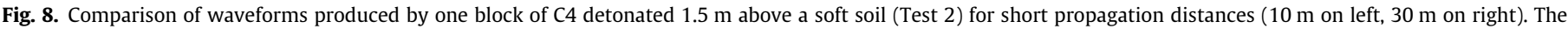

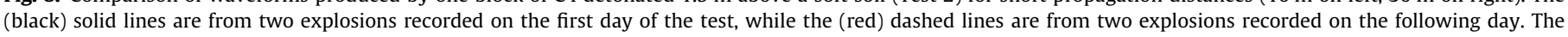

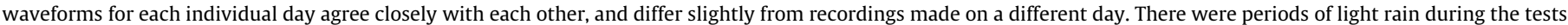
so the soil moisture as well as the atmospheric conditions were likely different on the two test days. (Color figure is available online.) 
C4 by dividing the propagation distance by the cube root of the actual charge mass and are shown in Figs. 9 and 10.

The left panel in Fig. 9 shows the peak positive pressure as a function of scaled propagation distance. The thick line is the ANSI Standard [47] predicted line for $1 \mathrm{~kg}$ of $\mathrm{C} 4$ and the thin line represents a least squares fit to the measured data of the same form as Eq. (2).

$P(R)=P_{0} R^{-\alpha}$

with an acoustic attenuation rate $\alpha$ of -1.2 . A straight line provides a good fit to the measured amplitudes. This coefficient can be interpreted as a geometric spreading factor of -1.0 and an additional material attenuation of -0.2 caused by losses from interaction with the ground surface, meteorological effects, and air absorption. The measured maximum pressure values lie on or below the ANSI Standard line. Most of the measured data lie above the overpressure damage criterion of $159 \mathrm{~Pa}$, indicated by the horizontal dashed line in the figure. For the different individual tests, maximum pressure attenuation rates $\alpha$ varied between -1.2 and -1.5 (Table 2). The highest attenuation rates were measured for the soft soil/gravel pile experiments of Test 3.

The right panel in Fig. 9 shows the maximum amplitude of the two seismic arrivals as a function of scaled propagation distance. The seismic amplitude $V_{\max }$ is the vector magnitude, calculated as

$V_{\text {max }}=\left(\dot{x}_{\text {max }}^{2}+\dot{y}_{\text {max }}^{2}+\dot{z}_{\text {max }}^{2}\right)^{1 / 2}$

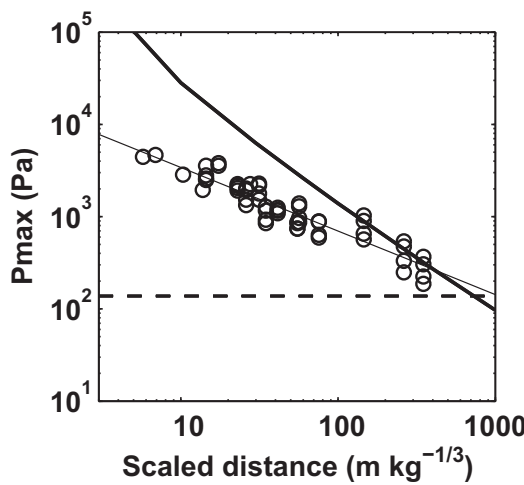

where $\dot{x}_{\max }^{2}$, etc. are the maximum vertical, radial, and transverse particle velocities measured by the geophones during the appropriate time period. This definition of vibration amplitude contrasts with previous studies that used only vertical component amplitudes. The vector magnitude is used here because the experimental measurements (and other unpublished measurements) show that the vertical and radial components sometimes differ by a factor of 10 or more depending on the site conditions, and that either component may dominate the other. Using the vector magnitude gives a more stable and realistic estimate of the total induced ground vibration than specified by a single component. The transverse component was included where available, but it was always much smaller than the two other components as expected from elastic wave theory.

Both the seismic arrivals associated with the acoustic arrival (circles) and the precursor seismic arrivals $(x)$ are shown in this plot. These correspond to Paths A and Path B in Fig. 1, and the graph shows that the precursor seismic arrival is two orders of magnitude below the maximum amplitude of the acoustically-induced seismic vibration. This difference in the amplitudes of the two seismic waves was observed at all test sites and is an important observation as there are occasionally civilian complaints filed claiming that the precursor seismic wave produced cosmetic damage to houses located near artillery training ranges. These observations show that any cosmetic damage would have to be caused by the higher amplitude air-coupled seismic wave arrival. It is likely

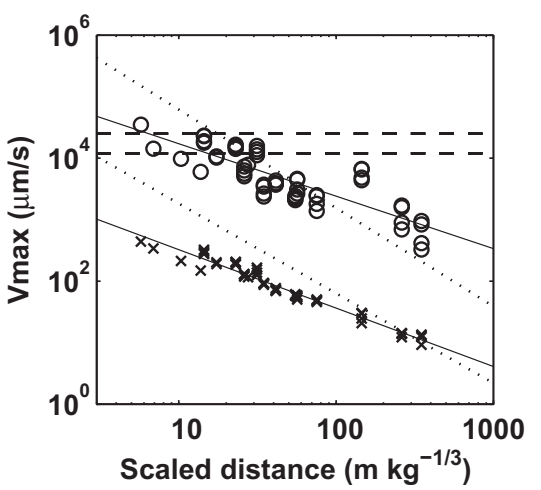

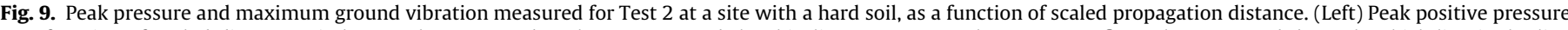

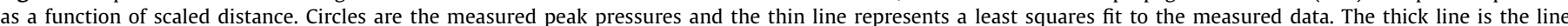

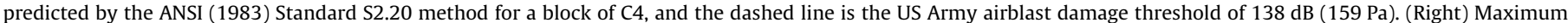

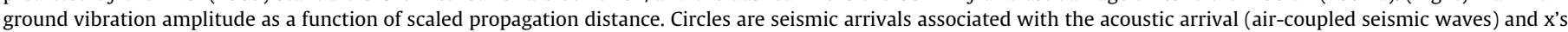

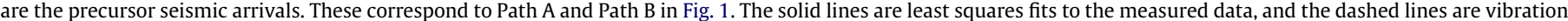

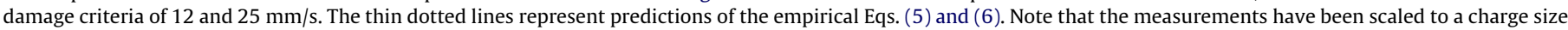
of $1 \mathrm{~kg}$ by dividing the distance by the cube root of the actual charge weight in $\mathrm{kg}$.
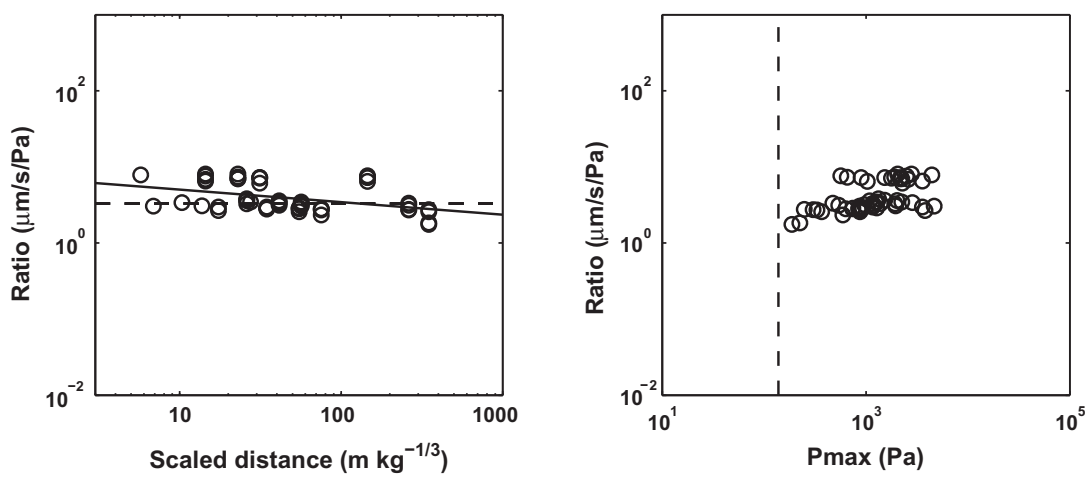

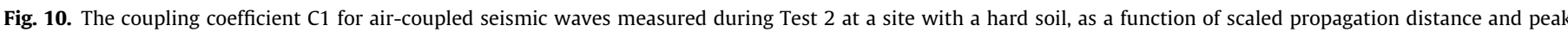

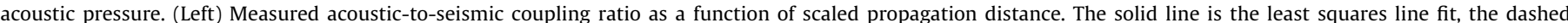

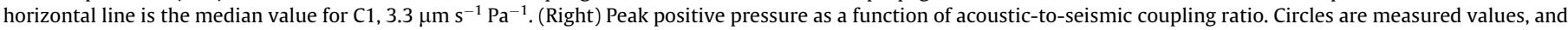
the dashed line is the Army airblast damage criterion of $138 \mathrm{~dB}$. 
Table 2

Measurement results, including attenuation rates vs. distance, coupling ratios, and peak pressures needed to exceed vibrational damage criteria.

\begin{tabular}{|c|c|c|c|c|c|c|c|c|c|c|c|c|c|}
\hline Test \# & Type & $\begin{array}{l}\text { Charge } \\
\text { size (kg) }\end{array}$ & $\begin{array}{l}\text { Distance } \\
\text { range }(\mathrm{m})\end{array}$ & $N$ & $\alpha$ & $\beta$ & $\begin{array}{l}\text { C1 S/A Ratio } \\
(\mu \mathrm{m} / \mathrm{s} / \mathrm{Pa})\end{array}$ & Slope of Ratio & $P-V$ & $\begin{array}{l}12 \mathrm{~mm} / \mathrm{s} \\
(\mathrm{kPa})\end{array}$ & $\begin{array}{l}12 \mathrm{~mm} / \mathrm{s} \\
(\mathrm{dB})\end{array}$ & $\begin{array}{l}25 \mathrm{~mm} / \mathrm{s} \\
(\mathrm{kPa})\end{array}$ & $\begin{array}{l}25 \mathrm{~mm} / \mathrm{s} \\
(\mathrm{dB})\end{array}$ \\
\hline 1 & Concrete & 0.57 & $8-91$ & 166 & -1.3 & -1.2 & 3.1 & 0.15 & 0.88 & 3.9 & 165.8 & 8.3 & 172.4 \\
\hline 2 & Soil & $0.57-72.7$ & $100-240$ & 54 & -1.2 & -1.6 & 3.3 & -0.43 & 1.3 & 2.3 & 161.2 & 3.7 & 165.3 \\
\hline 3 & Soil and Gravel pile & 0.57 & $60-405$ & 292 & -1.5 & -1.1 & 5.7 & 0.36 & 0.76 & 2.2 & 160.8 & 4.8 & 167.6 \\
\hline 4 & Tropical vegetation & $0.28-4.5$ & $30-100$ & 110 & -1.3 & -1.5 & 13.2 & -0.18 & 1.1 & 1.0 & 154.0 & 1.6 & 158.1 \\
\hline 5 & Forest & $0.57-2.3$ & $30-565$ & 138 & -1.3 & -1.4 & 5.2 & -0.12 & 1.1 & 1.8 & 159.1 & 3.7 & 165.3 \\
\hline 6 & Snow/frozen ground & $0.28-4.5$ & $30-100$ & 143 & -1.3 & -1.1 & 1.0 & 0.22 & 0.87 & 12.3 & 175.8 & 25.6 & 182.1 \\
\hline 7 & Deep Snow & $0.28-4.5$ & 60,150 & 33 & -1.5 & -1.3 & 34.2 & 0.17 & 0.85 & 0.33 & 144.3 & 0.76 & 151.6 \\
\hline 1-6 & Combined & & & 903 & -1.40 & -1.1 & 4.7 & 0.33 & 0.75 & 2.0 & 160.0 & 3.5 & 164.9 \\
\hline
\end{tabular}

$\mathrm{N}=$ number of measurements.

$\alpha=$ decay rate coefficient for maximum acoustic pressure.

$\beta=$ decay rate coefficient for maximum seismic amplitude.

Ratio = slope of the Seismic/Acoustic ratio vs. scaled distance

$\mathrm{S} / \mathrm{A}$ Ratio $=$ median value of seismic/acoustic amplitudes $\left[\mu \mathrm{m} \mathrm{s}^{-1} \mathrm{~Pa}^{-1}\right]$. This value corresponds to coefficient $\mathrm{C} 1 \mathrm{defined}$ in Fig. 1 and in Eq. (10).

$P-V=$ Slope of the $P_{\max }-V_{\max }$ line in Fig. 19.

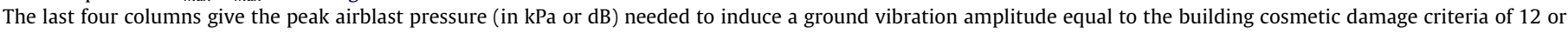
$25 \mathrm{~mm} / \mathrm{s}$.

that all civilian complaints were actually from perceived vibrations induced by the airblast, not by the seismic precursor. The airblast is not often heard by an observer located inside a dwelling at long distances, so window rattling and other vibrations can be easily mistaken and reported as a seismic arrival.

Both the precursor and the air-coupled seismic maximum amplitudes can be reasonably fitted by least squares lines as shown by the dashed lines in Fig. 9. These equations have the form

$V_{\max }=V_{0}\left(R_{0}\right)\left(R / W^{1 / 3}\right)^{-\beta}$

where $\beta$ is the seismic attenuation rate that includes both geometric divergence and material losses. The solid lines are least squares lines fitted to the vibration measurements, and the line fitted to $V_{\max }$ gives an amplitude decay rate $\beta$ for the air-coupled seismic wave of -1.6 (listed in Table 2). Because the precursor seismic amplitudes are so much smaller than the air-coupled seismic wave amplitudes, the attenuation rates of these waves are omitted from Table 2. The dotted lines shown in the figure were calculated from Dowding's [37] empirical equations, Eqs. (5) and (6) above. For these measurements, Eq. (5) slightly underpredicts the measured maximum air-coupled vibration data and predicts a higher attenuation rate. Eq. (6), for buried explosives, predicts values that fit the precursor seismic arrival amplitudes relatively well, but because of the low amplitudes of these waves this equation is unsuitable for predicting the cosmetic damage levels produced by this typical military case. All of the precursor seismic wave amplitudes and most of the air-coupled seismic wave amplitudes lie below the damage criteria of 25 or $12 \mathrm{~mm} \mathrm{~s}^{-1}$, indicated by the horizontal lines in the Figure.

The least squares line fit to the air-coupled seismic waves can be used to predict when the seismic amplitude will exceed the damage criteria for this test. In this case, a scaled stand-off distance of less than $100 \mathrm{~m} \mathrm{~kg}^{-1 / 3}$ from the explosion is needed before damage is expected, a value far less than allowed in military training.

The seismic vibration induced by the airblast can be characterized by the ratio of seismic vibration per Pa of overpressure as in the definition of coefficient $\mathrm{C} 1$ in Fig. 1. For air-coupled seismic waves, the relationship can be written as

$C 1=V_{\max } / P_{\max }(R)$

where $V_{\max }$ is the maximum particle velocity, $P_{\max }$ the maximum pressure, and $\mathrm{C} 1$ is the acoustic-to-seismic coupling coefficient for air-coupled seismic waves. A similar equation can be written for $\mathrm{C} 2$, the coupling coefficient for precursor seismic waves, where the variables will be evaluated at small distances $\mathrm{R}$ close to the explosive source.
Fig. 10 shows the measurements of the ratio of the maximum air-coupled seismic wave amplitude to the maximum air pressure wave for Test 2 over a hard soil. The left panel shows the measured acoustic-to-seismic coupling ratio vs. scaled propagation distance, and the right panel the ratio vs. the maximum pressure. There are two groups of data points visible in these plots. The group with the higher ratio consists of all of the measurements from the $100 \mathrm{~m}$ sensor location, while the lower group consists of all of the measurements from the 120,180 , and $240 \mathrm{~m}$ locations. While the $100 \mathrm{~m}$ location gave consistently higher ratios (nearly twice as high as the other locations), careful examination of all of the waveforms for all locations gave no reason to reject any of the measurements. The difference in the ratio is probably caused by differences in local soil conditions. Rain fell during the tests, and the results could also have been influenced by differences in soil moisture at each sensor location.

On the left panel, the solid line is the least squares line fit to the measured data, while the dotted line indicates the median value for the coefficient $\mathrm{C} 1,3.3 \mu \mathrm{m} \mathrm{s}^{-1} \mathrm{~Pa}^{-1}$. When the data from all of the different tests were examined, some least squares lines had positive and some had negative slopes; all of the slopes were small $( \pm 0.4)$. There does not appear to be a dependence of the ratio on propagation distance, but instead a constant value was obtained at each test site. The median value appeared to be the most useful fit to the measured data, and is listed in Table 2 for all tests. This is the measured value of the coupling coefficient $\mathrm{C} 1$ for air-coupled seismic waves in Fig. 1.

\subsubsection{Maximum amplitudes for combined Tests 1-6 - propagation in various environments}

Fig. 11 shows the maximum acoustic and seismic amplitudes measured during Tests 1-6 in a variety of ground environments. The Figure shows that most of the 903 pressure measurements are on or below the ANSI Standard [47] prediction. The maximum pressure is equaled or exceeded only by a small percentage of the measurements over the hardest grounds, concrete, frozen soil, or a hard soil (Tests 1, 2, 6). The acoustic maximum pressure for the combined measurements has an attenuation coefficient $\alpha$ of -1.40 .

The air-coupled seismic amplitudes and the precursor seismic amplitudes are shown in the right panel of Fig. 11. Here, the precursor seismic amplitudes are about two orders of magnitude less than the air-coupled seismic waves because of the higher seismic attenuation. Close to the source, the precursor seismic and aircoupled seismic arrival times are very close and the early arrival identification was somewhat arbitrary so there is a lot of scatter in the amplitude of the early arrival for short propagation 

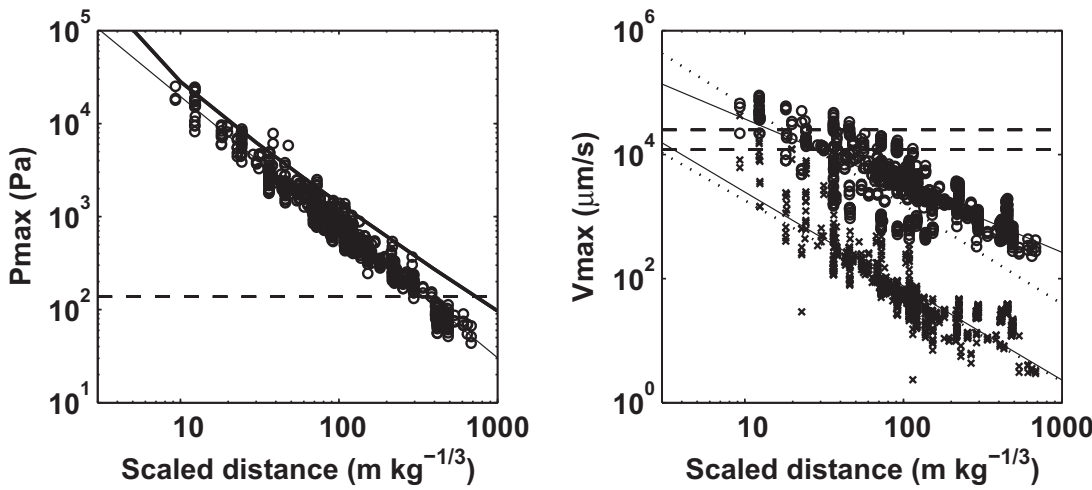

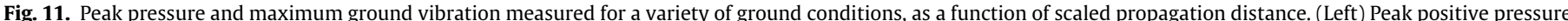

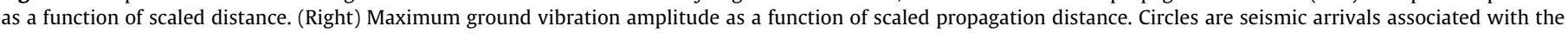
acoustic arrival (air-coupled seismic waves) and x's are the precursor seismic arrivals. See the caption to Fig. 9 for identification of the lines on the plots.
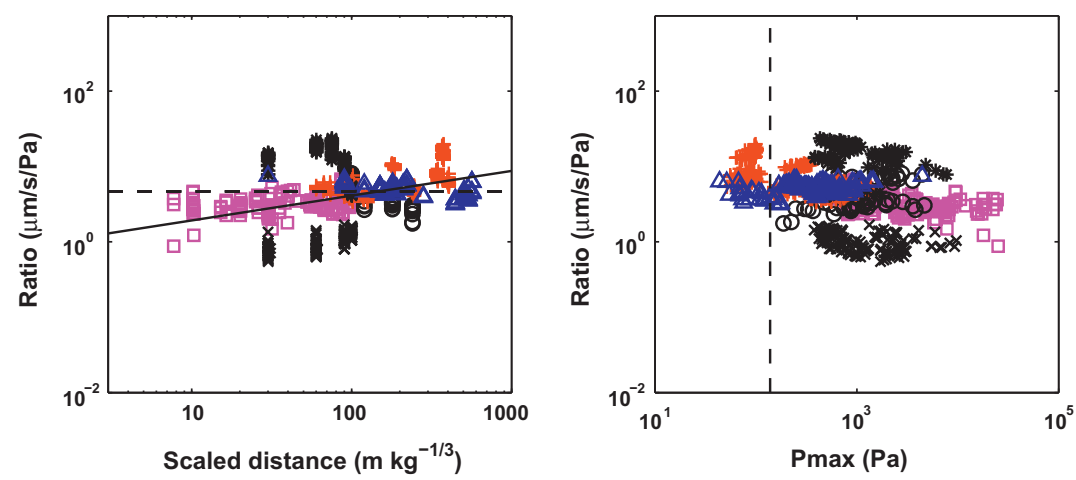

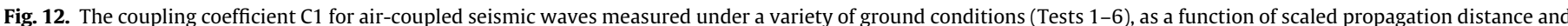

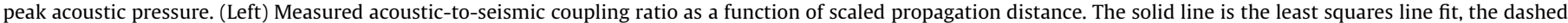

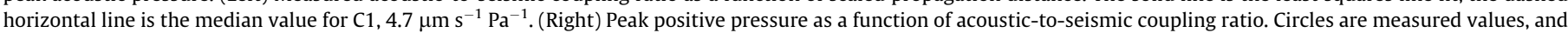

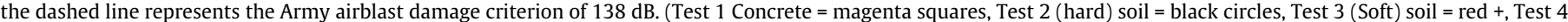
Tropical vegetation = black ${ }^{*}$, Test 5 Forest = blue triangles, Test 6 Snow and frozen ground = black X). (Color figure is available online.)

distances. The attenuation coefficient for the air-coupled seismic waves was -1.1 , while that of the precursor seismic waves was -1.47 .

Fig. 12 shows the ratios of the measured air-coupled seismic to acoustic amplitudes as a function of scaled distance and maximum pressure. The plots of the individual tests showed that each sensor location has its own constant value of this ratio independent of the propagation distance or acoustic wave amplitude. The results for each test are given in Table 3. For the combined measurements, the median value is $4.7 \mu \mathrm{m} \mathrm{s}^{-1} \mathrm{~Pa}^{-1}$ with a standard deviation of 4.5. While the values range from 0.6 to $23.6 \mu \mathrm{m} \mathrm{s}^{-1} \mathrm{~Pa}^{-1}$, the 5 th and 95th percentile values are 2.2 and $7.5 \mu \mathrm{m} \mathrm{s}^{-1} \mathrm{~Pa}^{-1}$, a fairly narrow range of values.

Results for the individual test measurements are listed in Table 3. The highest measured value for this parameter was
$13.2 \mu \mathrm{m} \mathrm{s}^{-1} \mathrm{~Pa}^{-1}$ for Test 4 over tropical vegetation. The vegetative ground cover is apparently a good material for coupling acoustic energy into the ground. This behavior can be explained by the lower acoustic and vibrational impedance of relatively porous materials compared to low or negligible porosity materials like soil and concrete. The lowest value measured was for Test 6 , propagation over hard frozen soil under a thin, weak snow cover, where the ratio was $1.0 \mu \mathrm{m} \mathrm{s}^{-1} \mathrm{~Pa}^{-1}$. This low value was obtained as a result of locating the sensors in the very hard frozen ground present at this site. Concrete had the next lowest value, $3.1 \mu \mathrm{m} \mathrm{s}^{-1} \mathrm{~Pa}^{-1}$.

Table 4 lists previously published values of the coupling coefficient $\mathrm{C} 1$ based on measurements using acoustic pulses. Despite the wide range of acoustic sources, propagation distances, and frequency bands used in the measurements, the values are all between 0.13 and $10 \mu \mathrm{m} \mathrm{s}^{-1} \mathrm{~Pa}^{-1}$ in general agreement with the

Table 3

Measured values of $\mathrm{C} 1$, the air-coupled seismic wave coefficient $\left[\mu \mathrm{m} \mathrm{s}^{-1} \mathrm{~Pa}^{-1}\right]$. The data are plotted in Fig. 12 .

\begin{tabular}{|c|c|c|c|c|c|c|c|c|}
\hline Test \# & Type & $\mathrm{N}$ & Median & Max & Min & Std & 95\%tile & 5th\%tile \\
\hline 1 & Concrete & 166 & 3.1 & 6.8 & 0.87 & 0.95 & 4.1 & 2.7 \\
\hline 2 & Soil & 55 & 3.3 & 8.1 & 1.8 & 2.0 & 4.2 & 1.9 \\
\hline 3 & Soil and Gravel pile & 292 & 5.7 & 19.7 & 3.4 & 3.4 & 4.2 & 8.8 \\
\hline 4 & Tropical vegetation & 110 & 13.2 & 23.6 & 4.1 & 5.6 & 9.6 & 12.7 \\
\hline 7 & Forest & 138 & 5.2 & 7.5 & 3.1 & 0.84 & 6.2 & 5.3 \\
\hline 6 & Snow/frozen ground & 143 & 1.0 & 1.7 & 0.55 & 0.28 & 1.1 & 1.4 \\
\hline 7 & Deep Snow & 33 & 34.2 & 50.8 & 26.0 & 6.6 & 34.6 & 27.3 \\
\hline 1-6 & Combined & 904 & 4.7 & 23.6 & 0.55 & 4.5 & 7.5 & 2.2 \\
\hline
\end{tabular}


Table 4

Previously reported acoustic pulse measurements for $\mathrm{C} 1$, the air-coupled seismic wave coefficient.

\begin{tabular}{|c|c|c|c|c|c|}
\hline $\mathrm{C} 1$, coupling coefficient $\left(\mu \mathrm{m} \mathrm{s}^{-1} \mathrm{~Pa}^{-1}\right]$ & Ground type & Acoustic source & Distance of source from sensors & $\begin{array}{l}\text { Estimated measurement } \\
\text { bandwidth }(\mathrm{Hz})\end{array}$ & Notes \\
\hline 0.25 & Sand & Artillery shell impact & $\sim 6 \mathrm{~km}$ & $2-500$ & 1 \\
\hline 2.2 & Sand & $230 \mathrm{~kg}$ bomb & $\sim 1 \mathrm{~km}$ & $2-500$ & 2 \\
\hline 6.3 & Loess & Propane cannon & $20 \mathrm{~m}$ & & 3 \\
\hline $6.9 \pm 0.4$ & Soil with grass & Blank pistol shot & $5-274 \mathrm{~m}$ & $5-500$ & 4 \\
\hline $5.9 \pm 0.6$ & Snow & Blank pistol shot & $5-274 \mathrm{~m}$ & $5-500$ & 4 \\
\hline $0.5-9.4$ & Sedimentary soil & $1500 \mathrm{~kg}$ explosions & $21 \mathrm{~km}$ & $1-20$ & 5 \\
\hline $0.13-0.23$ & Soil & Sonic boom & Various (tens to hundreds of $\mathrm{km}$ ) & $1-20$ & 6 \\
\hline $1.5-2.5$ & Soft/hard rock & Sonic boom & - & - & 7 \\
\hline 10 & Soil & 1-64 kg explosions & $2-17 \mathrm{~m}$ & $5-30$ & 8 \\
\hline
\end{tabular}

Notes: 1. Estimated from Fig. 1 of Sabatier and Raspet [16].

2. Estimated from Fig. 2 of Sabatier and Raspet [16].

3. Estimated from Fig. 4 of Sabatier and Raspet [16].

4. Albert and Orcutt [22]. The snow cover was $25 \mathrm{~cm}$ deep with densities of $190-290 \mathrm{~kg} \mathrm{~m}^{-3}$.

5. Estimated from Fig. 3 of Kitov et al. [23].

6. Estimated from Cates and Sturtevant [6].

7. Unpublished report by Goforth and McDonald (1968), quoted by Cates and Sturtevant [6].

8. Estimated from Fig. 9 of Madshus et al. [15].

values reported here. While acoustic-to-seismic coupling ratios have also been measured using continuous wave acoustic source produced by loudspeakers, these measurements are difficult to compare directly with pulse measurements because of the influence of soil resonant frequencies at short propagation distances; values can vary by more than a factor of 10 over adjacent frequency bins a few tens of $\mathrm{Hz}$ apart. In addition, most of the previous measurements were vertical component, not vector component seismic amplitudes. Bass et al. [26] reported values of 5-10 $\mu \mathrm{m} \mathrm{s}^{-1} \mathrm{~Pa}^{-1}$ for silt loam, while Sabatier et al. [27] reported maximum (resonant) values of $13 \mu \mathrm{m} \mathrm{s}^{-1} \mathrm{~Pa}^{-1}$ for dredged sand and $8 \mu \mathrm{m} \mathrm{s}^{-1} \mathrm{~Pa}^{-1}$ for loess; the values away from the resonant frequencies were about $2-3 \mu \mathrm{m} \mathrm{s}^{-1} \mathrm{~Pa}^{-1}$. Harrop and Attenborough [11] reported a maximum resonant amplitude of $45 \mu \mathrm{m} \mathrm{s}^{-1} \mathrm{~Pa}^{-1}$ for sand, but values between 3 and $15 \mu \mathrm{m} \mathrm{s}^{-1} \mathrm{~Pa}^{-1}$ at other frequencies.

Returning to Fig. 11, the least squares line fits to the maximum pressure and maximum precursor seismic waves can be used to estimate the coupling coefficient $\mathrm{C} 2$ for the precursor seismic wave path shown in Fig. 1 . This estimate is formed by calculating the ratio of the least squares predictions of the amplitude values for a propagation distance of $1.5 \mathrm{~m}$ (the height of most of the C4 explosive charges), and a value of $0.16 \mu \mathrm{m} \mathrm{s}^{-1} \mathrm{~Pa}^{-1}$ was obtained. This coupling coefficient is much smaller than the air-coupled seismic coefficient $\mathrm{C} 1$, perhaps due to nonlinear effects and higher attenuation of near-source terms that would be induced close to the explosive charge.

\section{Modeling ground vibration waveforms produced by explosions}

The simple model of blast sound interaction with the ground that is postulated above ignores any possible frequency dependence. To ensure that the process of acoustically-induced ground motion and its dependence on relevant factors is understood, the acoustic pressure and associated ground motion produced by propagation from a point source in air was calculated using a frequency-domain program. This modeling is found to provide additional insight to the processes inducing ground motion from airborne explosive sources.

Strictly, such modeling should include nonlinear effects near the explosive source. Although such a model has been developed for the above ground propagation it assumes the ground to be semi-infinite and rigid-porous $[48,49]$. To deal with the more complex problems posed by ground layering and elasticity, a (linear)
Fast Field Program for Layered Air Ground Systems (FFLAGS), developed originally for continuous sound sources [30], has been extended to enable predictions of acoustic and seismic pulses from explosions in a refracting atmosphere above layered porous and elastic ground. The code has been modified (i) to allow for an impulsive source, (ii) to enable predictions of pulse propagation above the ground and (iii) to enable predictions of the resulting solid vertical and radial particle velocities at the ground surface. The extended code is called PFFLAGS.

\subsection{Calculating acoustic propagation from a point source in air: PFFLAGS}

\subsubsection{Biot theory}

Biot [50-53] developed a theory of propagation of waves in a porous elastic medium by considering stresses and strains on fluid and solid components. Assuming a potential energy $W$ Biot wrote stress-strain relations in terms of derivatives of $W$. Through introduction of the kinetic energy, $T$, and the Lagrange's equations for the aggregate, the equations of coupled motion for the propagation of waves were derived. Viscous effects were included by adding a viscosity correction function to the equations to compensate for the breakdown of Poiseulle flow in the pores. Biot's equations of motion in two-phase media, as modified by Stoll [54], assuming time-harmonic potentials, are:

$$
\begin{aligned}
& \nabla^{2}\left(\bar{H} \phi_{s}-\bar{C} \phi_{f}\right)=-\omega^{2}\left(\rho \phi_{s}-\rho_{f} \phi_{f}\right), \\
& \nabla^{2}\left(\bar{C} \phi_{s}-\bar{M} \phi_{f}\right)=-\omega^{2}\left(\rho_{f} \phi_{s}-\rho^{\prime} \phi_{f}\right)
\end{aligned}
$$

where $\rho^{\prime}$ can be considered as a complex fluid density:

$\rho^{\prime}=m-\frac{i \eta}{\omega \kappa} F(\lambda)$

and

$m=q^{2} \rho_{f} / \Omega$

is a factor that accounts for extra inertia due to the fact that not all fluid flows along the axis of pores. The symbols $q^{2}$ and $\Omega$ represent tortuosity (related to the formation factor for electrical resistivity) and volume porosity of connected pores respectively. The symbols $\eta$ and $\kappa$ represent dynamic fluid viscosity and permeability respectively and $\omega$ is the angular frequency. The viscosity correction function, $F(\lambda)$, arises from the viscous drag of the fluid in the pores. It accounts for the breakdown of the Poiseuille flow in the pores and depends on a dimensionless parameter relating to the thickness 
of the boundary layer at the pore walls. In (13), $\eta F(\lambda)$ acts as a dynamic viscosity factor with

$\lambda=\frac{1}{2 s_{p}}\left(\frac{8 \rho_{0} q^{2} \omega}{\Omega \sigma}\right)^{1 / 2}=\left(\frac{2 \rho_{0} q^{2} \omega}{\Omega \sigma s_{p}^{2}}\right)^{1 / 2}$

Here $\sigma$ is the flow resistivity, with units of $\mathrm{N} \mathrm{s} \mathrm{m}^{-4}$ which represents the ratio of the applied pressure gradient within a porous material to the induced fluid volume velocity for steady flow. The parameter $s_{p}$ is a dynamic pore shape factor (=1 for cylindrical pores) $[55,56]$ and tortuosity is calculated from $\Omega^{-n^{\prime}}$ where $n^{\prime}$ is a grain shape factor ( $=0.5$ for spherical grains).

$H, C$ and $M$ are effective bulk moduli of elasticity. $H$ can be thought of as the corresponding effective modulus of the solid, while $C$ and $M$ are moduli involving coupling with the entrained fluid. The three (complex) moduli are determined from the solid and fluid bulk moduli of the constituent parts [54].

$H=\left[\frac{\left(k_{s}-k_{b}\right)^{2}}{D-k_{b}}+k_{b}+4 / 3 \mu\right]$,

$C=k_{s} \frac{\left(k_{s}-k_{b}\right)}{D-k_{b}}$,

and

$M=\frac{k_{s}^{2}}{D-k_{b}}$

where $k_{s}$ is the bulk modulus of the solid grains, $k_{b}$ is the bulk modulus of the drained solid matrix, $k_{f}$ is the bulk modulus of the pore fluid, and

$D=k_{s}\left[1+\Omega\left(\frac{k_{s}}{k_{f}}-1\right)\right]$.

In general, the fluid bulk modulus is influenced by the thermal drag experienced by the fluid in the pores and hence it is complex and frequency dependent. This is particularly important in airfilled pores.

The corresponding equations of motion for the rotational motion are:

$\mu \nabla^{2} \chi_{1}=-\omega^{2}\left(\rho \chi_{1}-\rho_{f} \chi_{2}\right)$,

$0=\left(\rho_{f} \chi_{1}-m \chi_{2}\right)-\frac{i \eta}{\kappa \omega} F(\lambda) \chi_{2}$

with $\mu$ being the rigidity of the material.

Writing the vector potentials $\chi_{1,2}$ in terms of a scalar potential $\varphi_{3}$ and using cylindrical coordinates:

$\tilde{\chi}_{1}=-\frac{\partial \phi_{3}}{\partial r} \hat{\theta}$

$\tilde{\chi}_{2}=m_{3} \tilde{\chi}_{1}$

The fluid rotational motion is proportional to the solid rotational motion (see Eq. (22)) means that it is coupled and not independent. This is the result of the assumption, made by Biot, that the fluid is an ideal fluid and does not support vorticity. The solid displacement $(\boldsymbol{u})$ and relative fluid displacement $(\boldsymbol{w})$ can be expressed in terms of the three potentials:

$\tilde{u}=\nabla \phi_{s}+\nabla \times \chi_{1}$,

$\tilde{w}=\Omega(\tilde{u}-\tilde{U})=\nabla \phi_{f}+m_{3} \nabla \times \chi_{1}$

Here, $U$ is the absolute fluid displacement and $w$ is the volume averaged relative fluid displacement.

Substitution of a plane wave potential in Biot's equations (11) and (12) and setting the coefficient determinant equal to zero, we obtain the following dispersion equation for the dilatational phase velocities: $\left(\rho_{f}^{2}-\rho \rho^{\prime}\right) v_{i}^{4}+\left(\bar{H} \rho^{\prime}+\rho \bar{M}-2 \rho_{f} \bar{C}\right) v_{i}^{2}+\left(\bar{C}^{2}-\overline{H M}\right)=0$

where $v_{i}\left(=\omega k_{i}\right)$ are the phase velocities. The resulting quartic equation has two roots. Frequently the two dilatational waves are called "fast" and "slow" waves. Both have components in the fluid as well as in the solid. The "fast" wave travels chiefly in the solid with little attenuation and is usually faster than the other wave in soils. It is very similar to the P-wave used in traditional (viscoelastic) seismic analysis. The "slow" wave, on the other hand, is highly attenuated and dispersive wave that travels mainly in the fluid and has a phase velocity that is typically less than the fluid acoustic velocity (hence the name). At audio frequencies in high flow resistivity soils, it is diffusive in nature. Biot points out that, in this wave, the solid and fluid are moving out of phase. Attenborough [55] has explored conditions under which the slow wave is similar to the 'pore wave' predicted in rigid porous media. There are, however, circumstances under which the slow wave also becomes a true propagating wave. This occurs at high porosity and high frequencies. If either $k_{b}=0$ (pure fluid) or $k_{f}=0$ (elastic limit) then the above equation has only one solution and the corresponding dispersion equation for a fluid or an elastic medium is retrieved.

The shear wave speed can be determined from equations for the rotational motion in a similar fashion

$v_{3}^{2}=\frac{\mu \rho^{\prime}}{\rho \rho^{\prime}-\rho_{f}^{2}}=\frac{\mu}{\rho-\rho_{f}^{2} / \rho^{\prime}}$

The single shear wave predicted in the porous elastic solid is very similar to the $\mathrm{S}$-wave in non-porous elastic media since the second term in the denominator is small.

\subsubsection{Fast Field Program (FFP)}

Each of two inhomogeneous media in contact (e.g. a fluid above a poro-elastic ground) is considered to consist of vertically stratified homogeneous layers. The system is assumed to be bounded from above by homogeneous fluid half-space and from below by a homogeneous solid half-space[57]. The wave equation in each layer, assuming a time dependence of $\exp (-i \omega t)$, is

$\nabla^{2} \Psi_{i}(r, z)+k_{i}^{2} \Psi_{i}(r, z)=\delta_{i}(r, z)$

where $\Psi i$ are the scalar displacement potentials for various wave types propagating in the medium, $k i\left(=\omega / c_{i}\right)$ are the corresponding wave numbers in layer $i$ and $\delta_{\mathrm{i}}$ represent source terms i.e. it is possible to consider multiple sources. One compressional wave propagates in the fluid. Two compressional waves and one shear wave may propagate in each porous elastic ground layer. The wave numbers for the ground waves are determined from the dispersion equations. Subscript $i=0$ is used to denote the fluid wave. Subscripts $i=1,2$ are used to denote the two compressional waves and $i=3$ is used for the shear wave in the solid layer. A cylindrical system of co-ordinates is employed throughout.

Noting that there is radial symmetry, to separate the radial and vertical variables in the equation and, thus, to reduce this partial differential equation to an ordinary one, a pair of Hankel transform integrals are used to represent the potentials:

$$
\begin{aligned}
& \Psi_{i}(r, z)=\int_{0}^{\infty} \psi_{i}\left(z, k_{r}\right) J_{0}\left(k_{r} r\right) k_{r} d k_{r} \\
& \text { and } \\
& \psi_{i}\left(z, k_{r}\right)=\int_{0}^{\infty} \Psi_{i}(r, z) J_{0}\left(k_{r} r\right) r d r
\end{aligned}
$$

where $J_{0}(z)$ is the zero order Bessel function and $k r$, the variable of integration, can be thought of as the horizontal or radial component of the wave number. Applying the second of these to the wave equation we obtain the transformed Helmholtz Equation:

$$
\frac{\partial^{2}}{\partial z^{2}} \psi_{i}+\beta_{i}^{2} \psi_{i}=S_{i} \delta(z)
$$


where

$\beta_{i}^{2}=k_{i}^{2}-k_{r}^{2}$

and the right hand side is the source term. In this way the problem of determining the wave amplitudes is reduced to one of solving a set of ordinary differential equations (ODE's). The boundary condition equations (BCE's) are put in the form of a Global Matrix equation

$\mathbf{A} \cdot \mathbf{X}=\mathbf{B}$

where $\mathbf{X}$ is a vector containing the wave amplitudes $\left(A_{i}\right.$ in the porous medium and $R_{i}$ in the fluid), A an $N \times N$ matrix containing the coefficients from the BCE's and $\mathbf{B}$ is the source term vector. The order of the matrix, $N$, is related to the number of fluid layers, $n_{f}$, and the number of solid layers, $n_{s}$, both including the half-space, by:

$N=6\left(n_{s}-1\right)+2 n_{f}+2$

The resulting matrix Eq. (31) can be solved by a variety of methods including Gaussian elimination with pivoting.

Subsequently the forward Hankel transform is applied to obtain the full wave solutions. The essence of the FFP technique is that once the Green's functions (the range-independent $\psi_{i}$ ) are known as a function of $k_{i}$, the transform can be replaced by a Fast Fourier Transform. This may be calculated in the far field by substituting a large argument approximation for the Bessel function. The integral can then be evaluated very quickly and efficiently using Discrete Fourier transform techniques available in signal processing. The inherent limitation in this process is that $k r r \gg 1$ which restricts the model to ranges greater than a couple of wavelengths from the source. The solution in the first fluid layer may be expressed by:

$\psi_{0}=R^{\uparrow} e^{j(z-h 1) \beta_{0}}+R^{\downarrow} e^{-j(z-h 2) \beta_{0}}$,

where, $h 1$ and $h 2$ denote the vertical coordinates of the lower and upper fluid layer boundaries ( $h 2>h 1)$ and $z$ is positive moving away from the fluid-solid interface.

Similarly for each poroelastic layer, there are three potentials given by

$\psi_{1}=A_{1}^{\downarrow} e^{j(z-d 1) \beta_{1}}+A_{1}^{\dagger} e^{-j(z-d 2) \beta_{1}}+A_{2}^{\downarrow} e^{j(z-d 1) \beta_{2}}+A_{2}^{\dagger} e^{-j(z-d 2) \beta_{2}}$

$\psi_{2}=m_{1}\left[A_{1}^{\downarrow} e^{j(z-d 1) \beta_{1}}+A_{1}^{\uparrow} e^{-j(z-d 2) \beta_{1}}\right]+m_{2}\left[A_{2}^{\downarrow} e^{j(z-d 1) \beta_{2}}\right.$

$\left.+A_{2}^{\uparrow} e^{-j(z-d 2) \beta_{2}}\right]$

$\psi_{3}=A_{3}^{\downarrow} e^{j(z-d 1) \beta_{3}}+A_{3}^{\dagger} e^{-j(z-d 2) \beta_{3}}$,

where, $d 1$ and $d 2$ denote the upper and lower solid boundaries $(|d 2|>|d 1|)$ and $\mathrm{z}$ is positive downwards from the interface. $R^{\downarrow}$ and $A_{n}^{\ddagger}(n=1,2,3)$ are the amplitudes to be determined from the boundary condition equations. Each potential consists of upgoing and downgoing terms. Also, because the two compressional wave types can exist simultaneously in solid and pore fluid phases, the potentials are a linear superposition of the two wave solutions with $m i$ being the appropriate ratios of solid-borne wave to pore-borne wave.

The required parameters for the boundary conditions involve the solid and fluid displacements and stresses. The fluid displacement is

$\nabla \Psi_{0}=\left(\frac{\partial \Psi_{0}}{\partial r}, \frac{\partial \Psi_{0}}{\partial z}\right)$

and the pressure is $\rho \omega^{2} \Psi_{0}$.

In the ground the solid phase displacement, $u$, is

$\tilde{u}=\nabla \Psi_{1}+\nabla \times \tilde{\chi}_{1}$

The radial and vertical components of solid displacement are given by

$u_{r}=\frac{\partial \Psi_{1}}{\partial r}+\frac{\partial^{2} \Psi_{3}}{\partial r \partial z}$

$u_{z}=\frac{\partial \Psi_{1}}{\partial z}-\frac{1}{r} \frac{\partial}{\partial r}\left(r \frac{\partial \Psi_{3}}{\partial r}\right)$
It is convenient to use the relative fluid motion and its components defined by

$\tilde{w}=\nabla \Psi_{2}+\nabla \times \tilde{\chi}_{2}$

$w_{r}=\frac{\partial \Psi_{2}}{\partial r}+m_{3} \frac{\partial^{2} \Psi_{3}}{\partial r \partial z}$,

$w_{z}=\frac{\partial \Psi_{2}}{\partial z}-m_{3} \frac{1}{r} \frac{\partial}{\partial r}\left(r \frac{\partial \Psi_{3}}{\partial r}\right)$

where, $\chi_{i}$ are vector potentials representing the transverse motion (see Eqs. (21) and (22)), and $m_{3}$ is the ratio of fluid rotational motion to the solid one.

\subsubsection{Pulse calculations}

To allow a time dependent acoustic source pulse $f_{S}(t)$ to be input to the continuous wave model [30], the source pulse is Fourier transformed in the time domain to obtain a pulse spectrum

$F_{S}(\omega)=\frac{1}{\sqrt{2 \pi}} \int_{t=0}^{\infty} e^{i \omega t} f_{S}(t) d t$

The wave amplitude $F$ at a point with cylindrical coordinates $\left(r_{m}, z\right)$ due to a unit source at $\left(0, z_{0}\right)$ for a given angular frequency $\omega$ is derived from Hankel transform of the one-dimensional solution of the wave equation, $\Gamma$ :

$F\left(r_{m}, z\right)=\frac{\Delta k \sqrt{N}}{2 \pi \sqrt{m}}\left(e^{-i \pi / 4} \sum_{n=0}^{N-1} \frac{\Gamma\left(k_{n}, z\right)}{\sqrt{n}} e^{2 i \pi m n / N}+e^{i \pi / 4} \sum_{n=0}^{N-1} \frac{\Gamma\left(k_{n}, z\right)}{\sqrt{n}} e^{2 i \pi m n / N}\right)$

where $N$ is the $n$ index upper bound for the finite summation evaluating the Hankel's transform, $m$ is the index for the range discretization, $r_{m}=m \Delta r=\frac{2 \pi m}{N \Delta k}$ is the range, $\Delta k=\frac{k_{\max }}{N-1}$ is the horizontal wave number increment and $k_{n}=n \Delta k . \Gamma\left(k_{n}, z\right)$ is the product of $k_{n}$ and the Green's function for the problem which is detailed elsewhere [30]. Eq. (42) is based on a large argument approximation of Bessel function and the replacement of the integration by a finite sum over index $n$ in the Hankel transform. Two Fast Fourier Transforms and correction factors are used to evaluate the sums in Eq. (42). The corrections are needed to allow for the truncation of the infinite integral associated with the Hankel transforms and for the presence of poles on the real axis. The integration contour is displaced by $\varepsilon \Delta k$ and a function $A\left(1-\exp \left(-\eta k_{N}\right)\right)$ is subtracted from the integrand in the Hankel transform, where $A$ can be expressed in terms of $N$, $\varepsilon, \eta$ and the integrand. The values of the correction parameters $\varepsilon$ and $\eta$ used for the calculations reported here are 1.1 and $3 / k_{\max }$ where $k_{\max }$ is the upper limit of the integration.

The predicted pulse spectrum is evaluated using Eqs. (41) and (42). The predicted time domain pulse follows from the inverse Fourier transform of the pulse spectrum as

$\Psi_{R}(t)=\frac{1}{\sqrt{2 \pi}} \int_{\omega=0}^{\infty} e^{-i \omega t} F_{s}(\omega) F\left(r_{m}, z, \omega\right) d \omega$

\subsubsection{Predictions over seismically-hard and -soft soil}

Predictions for two contrasting measurement sites (Tests 2 and 3 ) are compared with corresponding data in this section. No seismic refraction survey results are available at any of the sites.

In the light of the repeatability discussed earlier, for the predictions presented here the source acoustic pulse waveform has been deduced from other C4 measurements [49] at a distance that is assumed to lie beyond that involving nonlinear interaction and the amplitude and pulse length have been adjusted to fit the acoustic data obtained over 'hard' soil at $100 \mathrm{~m}$. The assumed source waveform is shown in Fig. 13. The spectral magnitude $P(f)$ calculated from an FFT of the assumed source pulse has a maximum power around $30 \mathrm{~Hz}$.

The pore-related parameters for the upper soil layers $\left(\sigma, \Omega, s_{p}\right.$, $\left.n^{\prime}\right)$ in tests 2 and 3 have been obtained by fitting the measured 


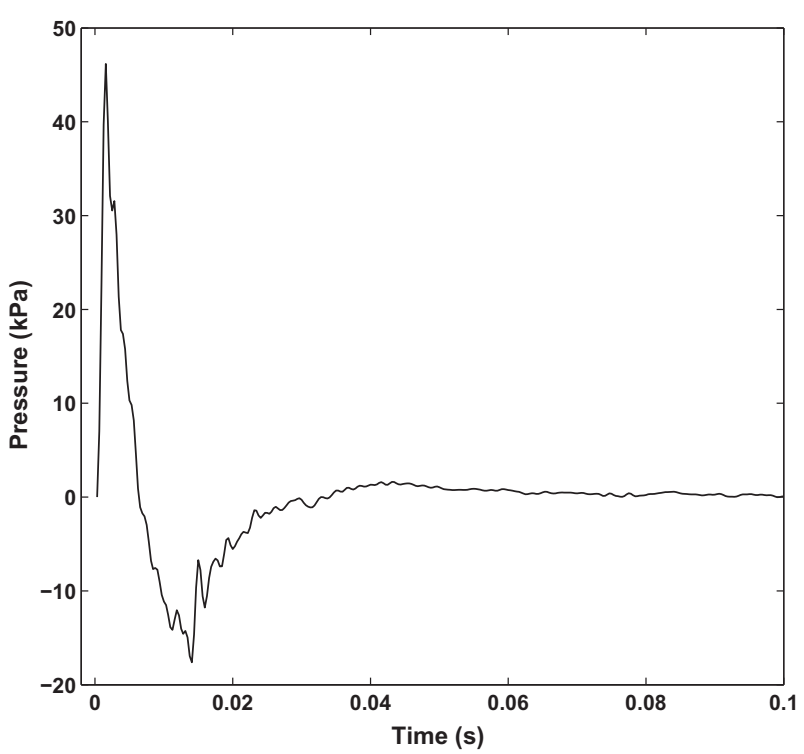

Fig. 13. Source pulse waveform assumed for predictions. It is based on measurements made close to C4 explosions [49 Vedy] with the peak amplitude adjusted to give a good fit to the 'hard' soil acoustic data at $100 \mathrm{~m}$ from Test 2.
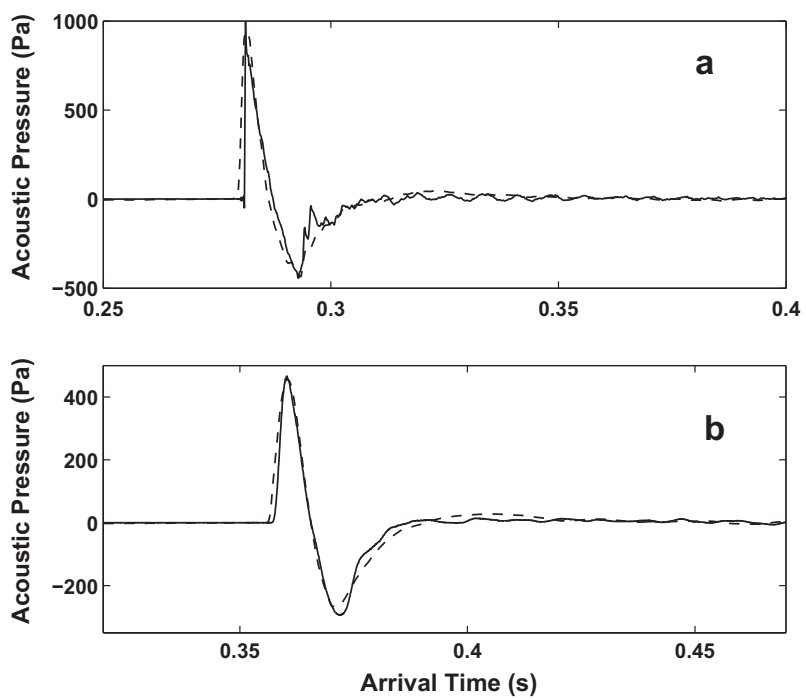

Fig. 14. Measurements (continuous lines) and predictions (broken lines) of the acoustic pulse waveforms with microphone on the ground (top) over 'hard' soil $100 \mathrm{~m}$ from the source and (bottom) over 'soft' soil $120 \mathrm{~m}$ from the source. The parameters used for the predictions are listed in Table 5. Although the adjustments to the assumed source waveform (Fig. 13) were made to give reasonable agreement with the 'hard' soil data at $100 \mathrm{~m}$ ((Fig. 14a), it is used without further modification to obtain the parameters for agreement with 'soft' soil data ((Fig. 14b).

acoustic pulses (Fig. 14). As might be expected a relatively high value of flow resistivity and a relatively low porosity value are necessary to fit the acoustic pulse data above the hard soil which is known to have been compacted. Conversely, the flow resistivity and porosity values required to fit the acoustic pulse above 'soft' soil are lower and higher respectively than the corresponding values for the 'hard' soil.

In the absence of seismic refraction information for the sites, a relatively simple model involving a single porous and elastic layer over a semi-infinite porous and elastic substrate has been assumed. The P- and S-wave speeds and thickness of the upper porous and elastic layers have been determined by trial and error fitting of the seismic data starting with typical values and fixing
Table 5

Ground parameters used for predictions (Figs. 14-16).

\begin{tabular}{lll}
\hline Parameter & Hard soil & Soft soil \\
\hline Speed of sound, deduced from time of flight $\left(\mathrm{ms}^{-1}\right)$ & 358.5 & 358.5 \\
No. of porous elastic layers (excluding substrate) & 1 & 1 \\
Layer & & \\
Flow resistivity $\left(\sigma \mathrm{N} \mathrm{s} \mathrm{m}^{-4}\right)$ & 927,000 & 127,000 \\
Porosity $(\Omega)$ & 0.17 & 0.37 \\
Pore shape factor $\left(s_{p}\right)$ & 0.3 & 0.3 \\
Grain shape factor $\left(n^{\prime}\right)$ & 0.5 & 0.5 \\
P-wave speed $\left(\mathrm{m} \mathrm{s}^{-1}\right)$ & 600 & 490 \\
S-wave speed $\left(\mathrm{m} \mathrm{s}^{-1}\right)$ & 400 & 290 \\
Soil density $\left(\rho \mathrm{kg} \mathrm{m}^{-3}\right)$ & 1700 & 1900 \\
Layer thickness $\left(\mathrm{m}^{\prime}\right)$ & 1.5 & 2.7 \\
Wave attenuation constant $(\alpha)$ & 0.02 & 0.02 \\
Substrate & & \\
Flow resistivity $\left(\mathrm{N} \mathrm{s} \mathrm{m}^{-4}\right)$ & $1,600,000$ & $1,600,000$ \\
Porosity & 0.07 & 0.07 \\
Pore shape factor & 0.3 & 0.3 \\
Grain shape factor & 0.5 & 0.5 \\
P-wave speed $\left(\mathrm{m} \mathrm{s}^{-1}\right)$ & 2040 & 2040 \\
S-wave speed $\left(\mathrm{m} \mathrm{s}^{-1}\right)$ & 1020 & 1020 \\
Soil density $\left(\mathrm{kg} \mathrm{m}^{-3}\right)$ & 2600 & 2600 \\
Wave attenuation constant $(\alpha)$ & 0.05 & 0.05 \\
\hline
\end{tabular}

the pore-related parameters at values that give good fits to the acoustic pulse data. The fitted values are listed in Table 5. The seismic wave speeds $\left(V_{p}=600 \mathrm{~m} / \mathrm{s}, V_{s}=400 \mathrm{~m} / \mathrm{s}\right)$ needed to fit the 'hard' soil data are higher than those $\left(V_{p}=490 \mathrm{~m} / \mathrm{s}, V_{s}=290 \mathrm{~m} / \mathrm{s}\right)$ that fit the 'soft' soil waveforms. One of the consequences of the assumed simple structure (a single $1.5 \mathrm{~m}$ thick layer over a higher wave speed substrate) for the predicted waveforms of the seismic signals in 'hard' soil (Fig. 15) is that, although they are consistent with $V_{p}>V_{s}>c$, they fail to include the prominent peaks in the measured waveforms which occur after the first arrivals. Probably these are the result of more complicated ground structures and more than the assumed two layers would be required to predict them.

On the other hand, based on the simple two-layer structure, the predicted seismic waveforms for the 'soft' soil (Fig. 16), as well as requiring a thicker upper layer $(2.7 \mathrm{~m})$, are able to reproduce the 'ringing' observed in both vertical and radial components. Moreover the values used for the predictions are such that $V_{p}>c>V_{s}$.

\subsubsection{Predictions for short range propagation over a snow layer}

The third waveform data set considered is from Test 6 , propagation over a thin snow layer, discussed earlier in this paper. A very low density and low strength snow cover was present at the site during the tests. Because the snow cover was very shallow the geophones were installed by drilling mounting holes into the frozen soil and freezing them in place.

Before testing the snow cover ranged from 10 to $15 \mathrm{~cm}$ in thickness and had an extremely low density of 130 to $330 \mathrm{~kg} \mathrm{~m}^{-3}$. As stated earlier various charge sizes of $\mathrm{C} 4$, ranging from 0.5 to 8 blocks $(0.28-4.5 \mathrm{~kg})$ were detonated on the surface and at a height of $1.5 \mathrm{~m}$ above ground level and the resulting signatures were measured using a digital seismograph for propagation distances of $30-100 \mathrm{~m}$. Snow characterization was carried out after the testing by which time a considerable area near the charge location was clear of snow.

Permeability measurements were conducted on cylindrical cores extracted near the $60 \mathrm{~m}$ sensor location and gave values of between 35 and $40 \times 10^{-10} \mathrm{~m}^{-2}$. The measured permeabilities correspond to flow resistivities between 4.47 and $5.1 \mathrm{kN} \mathrm{s} \mathrm{m}^{-4}$.

Example waveforms obtained at $100 \mathrm{~m}$ are shown in Fig. 17. There are significant secondary arrivals and a minor precursor in 

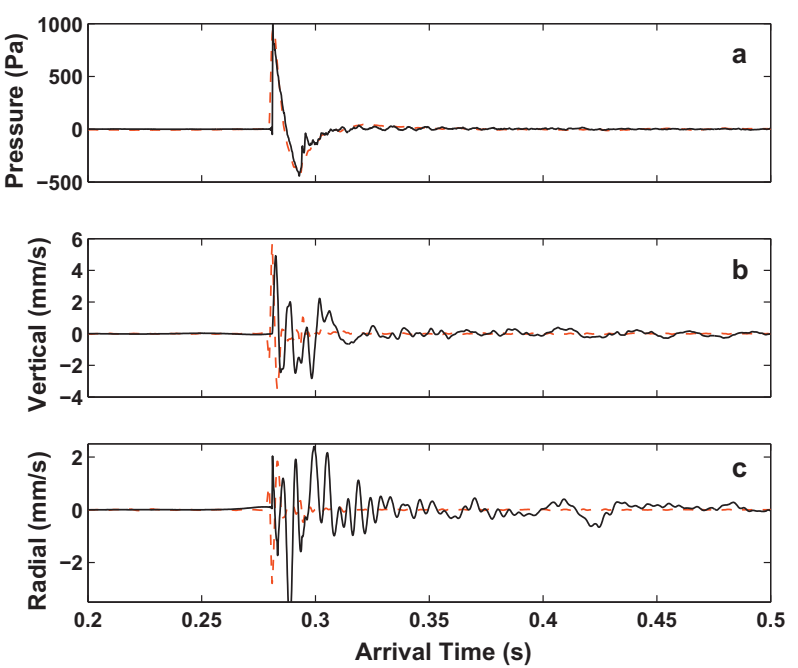

Fig. 15. Measured (continuous line) and predicted (dashed line) waveforms of (a) acoustic pressure, (b) soil vertical particle velocity and (c) soil radial particle velocity waveforms at a geophone buried at a depth of $1 \mathrm{~cm}$ in 'hard' soil $100 \mathrm{~m}$ from the source. The prominent late arrivals observed in the data for both vertical and radial seismic components are probably the result of multiple layers below the topsoil not included in the model. The parameters used for the predictions are listed in Table 5.
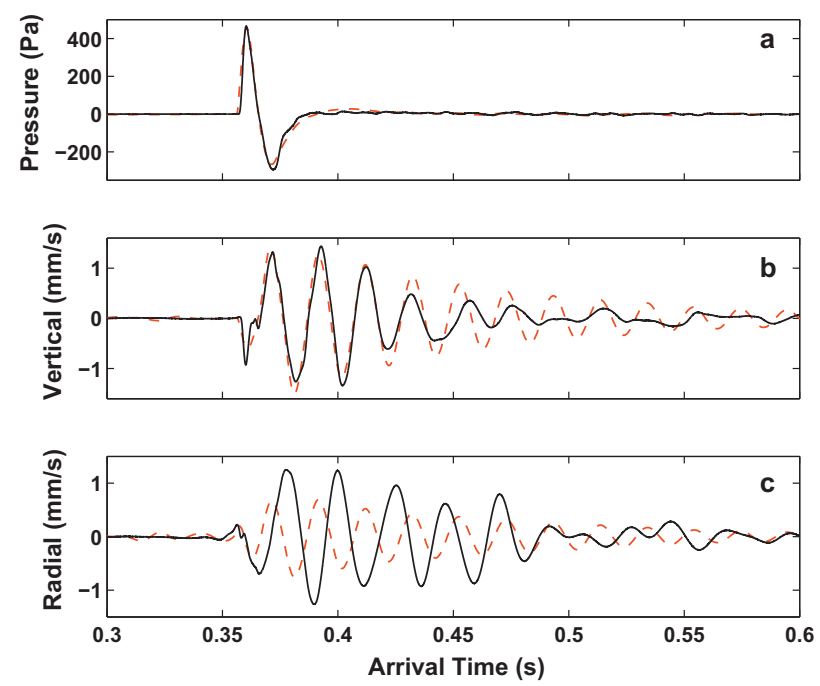

Fig. 16. Measured (continuous line) and predicted (dashed line) waveforms of (a) acoustic pressure, (b) soil vertical particle velocity and (c) soil radial particle velocity waveforms at a geophone buried at a depth of $1 \mathrm{~cm}$ in 'soft' soil located $120 \mathrm{~m}$ from the source. The parameters used for the predictions are listed in Table 5.

the vertical seismic component. There is a clear secondary arrival and a significant precursor in the radial seismic component.

Table 6 lists values used to obtain the waveform predictions to fit the data in Figs. 17 and 18. The best fit of the acoustic pulse data (Fig. 17a) is obtained by assuming that the snow has a surface crust. This is consistent with the actual density profile data. The total assumed thickness of the snow layer $(15 \mathrm{~cm})$ corresponds to the deepest section measured but the predictions are not very sensitive to the assumed thickness of the lower snow layer. The assumed flow resistivity of the snow layer beneath the crust is based on the snow core data The geophone is assumed to be at $16 \mathrm{~cm}$ depth i.e. just within the frozen ground layer.

The observed secondary arrival in the vertical seismic component (Fig. 17b) and the earliest precursor (Fig. 18a) are predicted
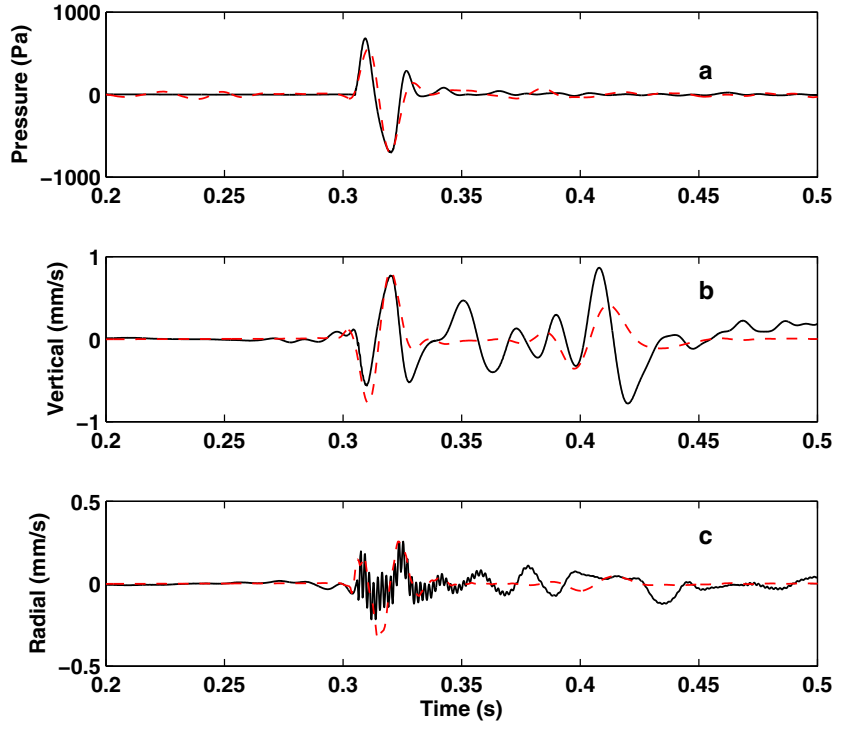

Fig. 17. Measured (continuous line) and predicted (dashed line) waveforms of (a) acoustic pressure, (b) soil vertical particle velocity and (c) soil radial particle velocity waveforms at a geophone buried at a depth of $1 \mathrm{~cm}$ in frozen ground beneath a snow cover, located $100 \mathrm{~m}$ from the source. The measurements are from Test 6 and the parameters used for the predictions are listed in Table 6. The calculated peak amplitudes were $0.9,2.1$, and 1.1 times as large as the measured peak amplitudes.

only if the frozen ground beneath the snow is assumed to have a substrate. The wave speeds and densities in the frozen ground and the substrate have been chosen to have reasonable values and to match the measured arrival time of the precursor. The assumed thickness of the frozen ground layer has been varied for best fit.

The values listed in Table 6 have been used to obtain the predictions of the main and secondary arrivals in the radial seismic component shown in Fig. 17c. However, to allow the predicted precursor to coincide with the measured one in Fig. 18b, the compressional wave speed in the substrate is assumed to be $490 \mathrm{~m} / \mathrm{s}$ (rather than $690 \mathrm{~m} / \mathrm{s}$ as in Table 6).

The measured precursors in the radial seismic component data are predicted only if the geophone is assumed to be at $14 \mathrm{~cm}$ depth or less i.e. within the snow layer. The agreement with data of the predicted time of the secondary arrival in Fig. 17c can be improved by assuming a shear wave speed of $249 \mathrm{~m} / \mathrm{s}$ for the substrate (instead of $244.5 \mathrm{~m} / \mathrm{s}$ ). However these adjustments would reduce the agreement obtained for the vertical component (Fig. 17b). The high frequency jitter in the main and secondary arrivals in the radial component signal (Fig. 17c) (which is more pronounced in Fig. 17c partly as a result of the different scale compared with Fig. 17b) may be due to sensor resonance. Nevertheless they are predicted to some extent if the radial component sensor is assumed to be inside the snow layer.

\subsubsection{Summary of waveform modeling results}

Although it would be possible to include atmospheric refraction in PFFLAGS predictions this has not been done so far. Other potential causes of discrepancies between PFFLAGS predictions and data include (i) nonlinear effects near the source (ii) range-dependent topography and lithography and (iii) atmospheric turbulence. The data fitting described would be more convincing if complete seismic and ground material characterization were available at either of the sites considered. Despite these limitations, it is considered that the numerical code PFFLAGS gives predictions that compare tolerably well with the data for waveforms of acoustic and seismic pulses in tests 2, 3 and 6 . 
Table 6

Fitted and measured parameters used for the Minnesota snow site predictions in Figs. 17 and 18.

\begin{tabular}{|c|c|c|c|c|}
\hline & 1st (Top) crusted snow layer & 2nd snow layer & Frozen ground layer & Unfrozen substrate \\
\hline$\sigma\left(\mathrm{kN} \mathrm{s} \mathrm{m}^{-4}\right)$ & 16 & 4 & 3000 & 300 \\
\hline$\Omega$ & 0.7 & 0.8 & 0.27 & 0.27 \\
\hline $\mathrm{S}_{f}=2 s_{p}$ & 0.6 & 0.8 & 0.72 & 0.72 \\
\hline$n^{\prime}$ & 0.5 & 0.5 & 0.5 & 0.5 \\
\hline$\rho\left(\mathrm{kg} \mathrm{m}^{-3}\right)$ & 330 & 130 & 2000 & 1700 \\
\hline$l(\mathrm{~m})$ & 0.02 & 0.13 & 0.2 & $\infty$ \\
\hline$V_{p}(\mathrm{~m} / \mathrm{s})$ & 410 & 230 & 1900 & 690 \\
\hline$V_{s}(\mathrm{~m} / \mathrm{s})$ & 280 & 160 & 1000 & 244.5 \\
\hline$\alpha$ & 0.007 & 0.007 & 0.01 & 0.007 \\
\hline
\end{tabular}
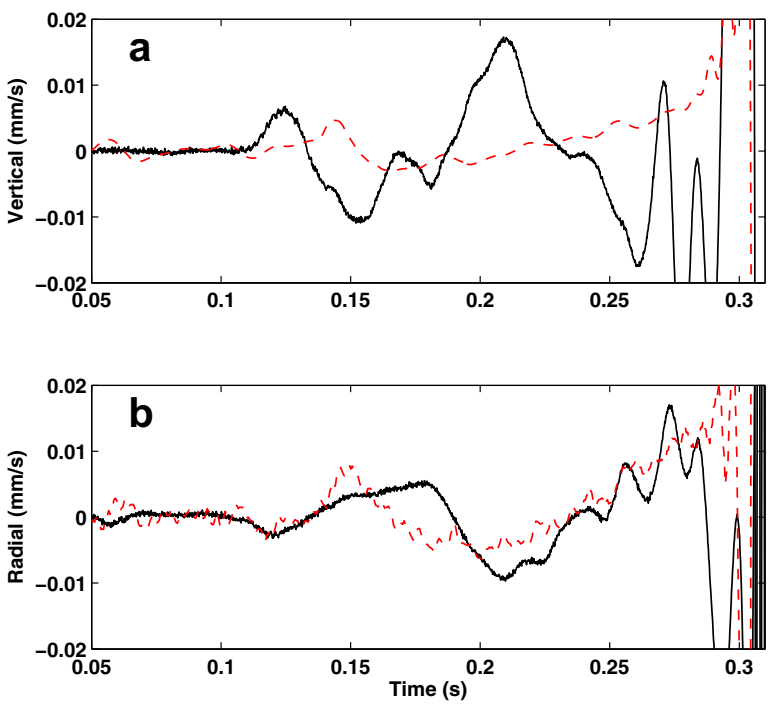

Fig. 18. Measured (continuous line) and predicted (dashed line) precursor waveforms (before the acoustic wave arrival) of (a) soil vertical particle velocity and (b) soil radial particle velocity waveforms at a geophone buried at a depth of $1 \mathrm{~cm}$ in frozen ground beneath a snow cover, located $100 \mathrm{~m}$ from the source. The calculated amplitude for the vertical component is approximately the same amplitude as the measured amplitude, but the calculated radial component has been multiplied by $\times 5$ for the lower plot.

For Test 6 , the best fits between predictions and vertical component seismic data from short range tests over snow up to $15 \mathrm{~cm}$ deep, using geophones placed in holes drilled into the frozen ground beneath the snow, are obtained by assuming (a) that the snow is crusted (b) that the frozen ground beneath the snow has finite thickness and (c) that the vertical component geophone is responding to signals in the frozen ground. On the other hand the best fit to the radial component data is obtained by assuming the geophone to be responding within the lower snow layer.

The main problem in applying this model is that many ground parameters are needed as input to the model, and some are not easily measured. Further work on the sensitivity of the model to the ground parameters would be useful. Nevertheless it has been shown using reasonable values for the parameters that it is possible to predict the observed difference between seismic signals measured in these three ground types. In particular model predictions have confirmed that the condition required for the 'ringing' observed in the seismic signals in 'soft' soils is that the speed of sound in air is less than the P-wave speed but greater than the Swave speed in the upper layer of soil.

\section{Empirical prediction of maximum ground vibration}

A conservative method to predict when ground vibration from military explosions in the air or on the ground might cause

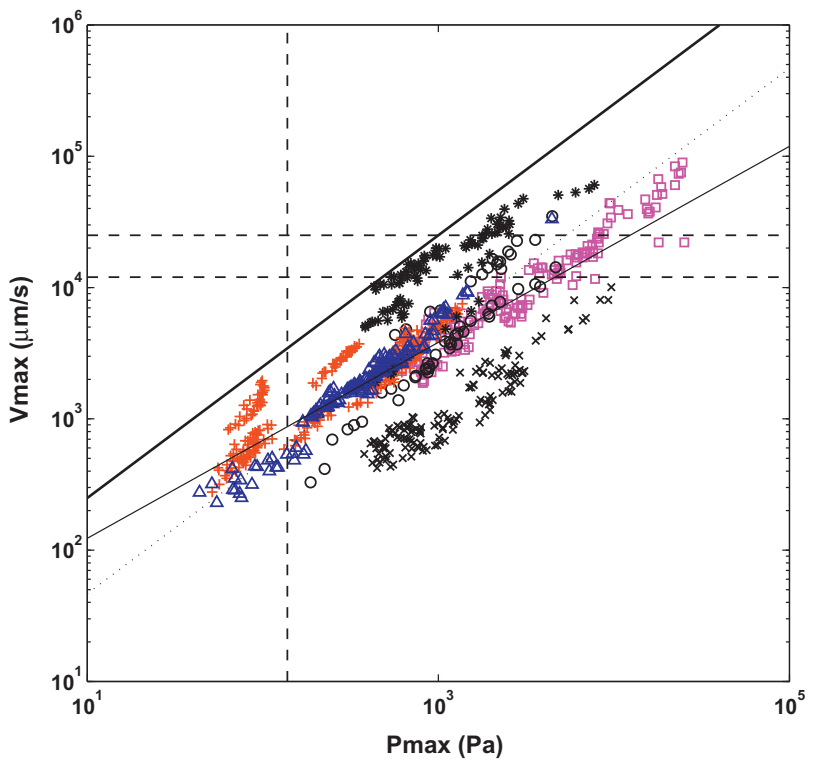

Fig. 19. Maximum pressure $\left(P_{\max }\right)$ vs. maximum induced vibration $\left(V_{\max }\right)$ measured during Tests 1-6 in a variety of environments. The dashed vertical and horizontal lines are the damage criteria of $138 \mathrm{~dB}, 12 \mathrm{~mm} / \mathrm{s}$, and $25 \mathrm{~mm} / \mathrm{s}$. The solid line running through the data represents a least squares fit to the measured data. The lightest dotted line through the data is a prediction given by Eq. (10), using the form $V_{\max }=P_{\text {ANSI }} *$ (Median Ratio) with the measured median coupling ratio $C 1,4.7 \mu \mathrm{m} / \mathrm{s}$ / $\mathrm{Pa}$. The heavy solid line above the data points parallel to this line is the empirical damage prediction given by Eq. (44). (Test 1 Concrete = magenta squares, Test 2 (hard) soil $=$ black circles, Test 3 (Soft) soil $=$ red + , Test 4 Tropical vegetation $=$ black *, Test 5 Forest = blue triangles, Test 6 Snow and frozen ground = black X). (Color figure is available online.)

cosmetic building damage is derived from the measurement data in this section. Because the measurement data have shown that vibration levels from the precursor seismic waves are always much smaller that those associated with the arrival of the air wave, these precursor waves are neglected in the prediction method. Data analysis also showed that the median value of the acoustic-to-seismic coupling coefficient $\mathrm{C} 1$ in Eq. (10) was $4.7 \mu \mathrm{m} \mathrm{s}^{-1} \mathrm{~Pa}^{-1}$. The highest measured value was $23.6 \mu \mathrm{m} \mathrm{s}^{-1} \mathrm{~Pa}^{-1}$ for a comparatively "springy" sensor location in tropical vegetation. In other locations the highest measured value was $19.7 \mu \mathrm{m} \mathrm{s}^{-1} \mathrm{~Pa}^{-1}$. To be conservative and overpredict the possible ground vibration, a coupling coefficient $C_{\max }$ is specified as $25 \mu \mathrm{m} \mathrm{s}^{-1} \mathrm{~Pa}^{-1}$, higher than any value measured in any ground experiment, and Eq. (10) is modified to read

$V_{\max }=C_{\max } P(R)$

This equation can be applied in two different ways. If an acoustic measurement of some military activity at the desired distance has been made or is available from past measurements, the measured 
peak positive pressure can be used as $P(R)$ in Eq. (44). Or, if a standard demolition event is planned with a known type and size of explosive charge a known distance away, the ANSI Standard [47] can be used to determine $P(R)$. In either case, Eq. (44) states that multiplying the measured or predicted maximum pressure in $\mathrm{kPa}$ by 25 determines the maximum particle velocity in $\mathrm{mm} \mathrm{s}^{-1}$. If the value is less than the damage threshold of 12 or $25 \mathrm{~mm} \mathrm{~s}^{-1}$, the activity should not cause any vibrational cosmetic damage.

Fig. 19 shows this equation plotted vs. the measured data from all of the Tests. The Figure shows that the equation overpredicts the measured ground vibration as desired. Eq. (15) predicts that the vibrational damage criteria of 12 and $25 \mathrm{~mm} / \mathrm{s}$ will be exceeded when the peak positive pressure exceeds $480 \mathrm{~Pa}$ $(147.6 \mathrm{~dB})$ or $1 \mathrm{kPa}(154.0 \mathrm{~dB})$, respectively. Either of these levels is much higher than the Army overpressure damage criterion of $159 \mathrm{~Pa}(138 \mathrm{~dB})$. Thus in most situations damage from blast overpressure will occur long before damaging levels of ground vibration are reached. For the precursor seismic waves, very large maximum acoustic pressures of 3.9 and $8.3 \mathrm{kPa}$ would be needed to reach the cosmetic damage criteria of 12 and $25 \mathrm{~mm} \mathrm{~s}^{-1}$.

\section{Summary}

DOD installations are increasingly dealing with complaints and damage claims alleging that military activities are producing bothersome ground vibrations. While some civilian regulations exist addressing ground vibration, DOD has not formally adopted any methods to regulate vibration or assess these complaints. In this paper, existing measurement data were analyzed to determine the noise and vibration produced by explosive detonations. The objective of this analysis was to produce a simple, accurate procedure for estimating the maximum ground vibration produced by Army training and demilitarization activities.

Analysis of the measured data showed that cube-root charge weight scaling is appropriate for predicting peak positive acoustic amplitudes, and the ANSI Standard S2.20 [47] provides good predictions of maximum pressures for small $\mathrm{C} 4$ explosions in different terrains. Measured acoustic pressure decay rates range from $r^{-1.2}$ to $r^{-1.5}$, compared to the ANSI Standard prediction of $r^{-1.2}$. The measured peak positive airblast pressures may exceed ANSI Standard prediction if the ground is very hard, or under highly favorable atmospheric conditions.

Two mechanisms and propagation paths for ground vibration were detected in all experiments as postulated. The seismic wave induced near the explosion source always arrived first and is followed by the wave coupled from the atmospheric wave on arrival at the receiver. The ground vibration induced by the arrival of the atmospheric wave is always greater than vibration from precursor seismic waves. The mechanisms and relative amplitudes of the ground vibration contributions at relatively short range have been confirmed by a frequency domain model which has been found also to explain the difference between seismic signals measured in 'hard' and 'soft' soils and to explain the frequency-modulation observed in data obtained over a thin snow layer. The acousticto-seismic coupling ratio $\mathrm{C} 1$ for the atmospheric wave is a constant with respect to distance and maximum pressure at a given location, but varies from site to site. For airborne explosions the value is usually between 1 and $13 \mu \mathrm{m} \mathrm{s}^{-1} \mathrm{~Pa}^{-1}$ (see Table 3 ).

A conservative empirical equation to predict ground vibration from explosions is given by Eq. (15). This equation predicts that the vibrational damage criteria of 12 and $25 \mathrm{~mm} / \mathrm{s}$ will be exceeded when the peak positive pressure exceeds $480 \mathrm{~Pa}$ $(147.6 \mathrm{~dB})$ or $1 \mathrm{kPa}(154.0 \mathrm{~dB})$, respectively. Either of these levels is much higher than the Army overpressure damage criterion of $159 \mathrm{~Pa}(138 \mathrm{~dB})$. Thus in most situations damage from blast overpressure will occur long before damaging levels of ground vibration are reached.

\section{Acknowledgements}

The measurements analyzed in this report came from a variety of sources. We would like to thank Mr. Richard Andrejkovics and Mr. Andre Edwin, US Army PM-CCS (Project Manager, Close Combat Systems) for funding Tests 1, 2, 4, and 6 as part of the Sympathetic Detonator (SYDET) project, and the many individuals from various government agencies who assisted in the management and conduct of these tests. Mr. Gary Leadore and Ms. Martha Turnbaugh of the US Army Aberdeen Test Center coordinated these tests. The measurements reported for Tests 3 and 5 were funded by Dr. Larry Pater, Project Leader for Military Noise Management, US Army ERDC-CERL. The snow pistol shot data used to confirm the theoretical waveform model and analysis support was provided by the US Army Corps of Engineers AT24 basic research program. Additional analysis support was provided through SERDP SEED Project SI-1410. Dr. Robert Holst served as the Sustainable Infrastructure Program Manager and Mr. Bradley Smith was the Executive Director. All of these contributions are gratefully acknowledged. We thank the editor and an anonymous reviewer for useful comments that have improved this paper. This paper is dedicated to the memory of Mr. Rich Andrejkovics.

\section{References}

[1] Becker G, Gudesen A. Passive sensing with acoustics on the battlefield. Appl Acoust 2000;59:149-78.

[2] Albert DG. The effect of snow on vehicle-generated seismic signatures. J Acoust Soc Am 1987;81:881-7.

[3] Anglin FM, Haddon RAW. Meteroid sonic shock-wave-generated seismic signals observed at a seismic array. Nature 1987;328:607-9.

[4] Kappus ME, Vernon FL. Acoustic signature of thunder from seismic records. J Geophys Res 1991;96:10989-1006.

[5] Lin T-L, Langston CA. Infrasound from thunder: a natural seismic source. Geophys Res Lett 2007;34.

[6] Cates JE, Sturtevant B. Seismic detection of sonic booms. J Acoust Soc Am 2002;111:614-28.

[7] Cook JC, Goforth T, Cook RK. Seismic and underwater responses to sonic booms. J Acoust Soc Am 1972;51:729-41.

[8] Kanamori H, Mori J, Anderson DL, Heaton TH. Seismic excitation by space shuttle. Nature 1991;349:781-2.

[9] McDonald JA, Goforth T. Seismic effects of sonic booms: empirical results. J Geophys Res 1969;74:2637-47.

[10] Arnott PW. Laser doppler vibrometer measurements of acoustic-to-seismic coupling. Appl Acoust 1990;30:279-91.

[11] Harrop N, Attenborough K. Laser-Doppler vibrometer measurements of acoustic-to-seismic coupling in unconsolidated soils. Appl Acoust 2002;63: 419-29.

[12] Scott Jr WR, Martin JS, Larson G. Experimental model for a seismic landmine detection system. IEEE Trans Geosci Remote Sensing 2001;39:1155-64.

[13] Veleau D, Waxler R, Sabatier JM. An effective fluid model for landmine detection using acoustic to seismic coupling. J Acoust Soc Am 2004;115: 1993-2002.

[14] Xiang N, Sabatier JM. An experimental study on antipersonnel landmine detection using acoustic-to-seismic coupling. J Acoust Soc Am 2003;113: 1333-41.

[15] Madshus C, Lovholt F, Kaynia A, Hole LR, Attenborough K, Taherzadah S. Airground interaction in long range propagation of low frequency sound and vibration. Appl Acoust 2005;66:553-78.

[16] Sabatier JM, Raspet R. Investigation of possibility of damage from the acoustically coupled seismic waveform from blast and artillery. J Acoust Soc Am 1988;84:1478-82.

[17] Ewing WM, Jardetzky WS, Press F. Elastic waves in layered media. New York: McGraw-Hill; 1957.

[18] Johnston AC. Air blast recognition and location using regional seismographic networks. Bull Seismol Soc Am 1987;77:1446-56.

[19] Press F, Ewing M. Ground roll coupling to atmospheric compressional waves. Geophysics 1951;16:416-30.

[20] Gupta IN, Hartenberger RA. Seismic phases and scaling associated with small high-explosive surface shots. Bull Seismol Soc Am 1981;71:1731-41.

[21] Anonymous. The response of songbirds to the seismic compression waves preceeding sonic booms. J Acoust Soc Am 1979;65:1066-7.

[22] Albert DG, Orcutt JA. Observations of low frequency acoustic-to-seismic coupling in the summer and winter. J Acoust Soc Am 1989;86:352-9. 
[23] Kitov IO, Murphy JR, Kunetsov OP, Barker BW, Nedoshivin NI. An analysis of seismic and acoustic signals measured from a series of atmospheric and nearsurface explosions. Bull Seismol Soc Am 1997;87:1553-62.

[24] Koper KD, Wallace TC, Reinke RE, Leverette JA. Empirical scaling laws for truck bomb explosions based on seismic and acoustic data. Bull Seismol Soc Am 2002;92:527-42.

[25] Ben-Menaham A, Singh SJ. Seismic waves and sources. New York: SpringerVerlag; 1981.

[26] Bass HE, Bolen LN, Cress D, Lundien J, Flohr M. Coupling of airborne sound into the earth: frequency dependence. J Acoust Soc Am 1980;67:1502-6.

[27] Sabatier JM, Bass HE, Bolen LN. Acoustically induced seismic waves. J Acoust Soc Am 1986;80:646-9.

[28] Sabatier JM, Bass HE, Bolen LN, Attenborough K, Sastry VVSS. The interaction of airborne sound with the porous ground: the theoretical formulation. J Acoust Soc Am 1986;79:1345-52.

[29] Attenborough K, Sabatier JM, Bass HE, Bolen LN. The acoustic transfer function at the surface of a layered poroelastic soil. J Acoust Soc Am 1986;79:1353-8.

[30] Tooms S, Taherzadah S, Attenborough K. Sound propagation in a refracting fluid above a layered porous and elastic medium. I Acoust Soc Am 1993;93:173-81.

[31] Dong H, Kaynia A, Madshus C, Hoven JM. Sound propagation over layered poroelastic ground using a finite-difference model. J Acoust Soc Am 2000;108: 494-502.

[32] Coward D, Blair JTD, Galybin K. Characterizing seismic noise in the $2-20 \mathrm{~Hz}$ band at a gravitational wave observatory. Rev Sci Instrum 2005;76: 044501.

[33] Aki K, Richards PG. Quantitative seismology: theory and methods, vol. 1. San Francisco: W.H. Freeman; 1980. p. 557.

[34] Amick H. A frequency-dependent soil propagation model. In: SPIE conference on current developments in vibration control for optomechanical systems. SPIE: Denver CO; 1999.

[35] Kinney GF, Graham KJ. Explosive shocks in air. 2nd ed. Berlin: Springer-Verlag; 1985.

[36] Wright WP. Army blast claims evaluation procedures. Adelphi, MD; 1994. p. 39.

[37] Dowding CH. Construction vibrations. Upper Saddle River, NJ: Prentice-Hall; 1996. p. 610.

[38] Siskind DE, Stagg MS, Kopp JW, Dowding CH. Structure response and damage produced by ground vibration from surface blasting; 1980. p. 74.

[39] Johnson et al. Underground storage in unlined rock tunnels: Rock mechanics considerations in estimating damage levels, in DOD Safety Board, Minutes of the Twenty-Third Explosives Safety Seminar; 1988. 1815 [The authors were unable to locate this paper cited by Wright (1994)].

[40] Ambrayseys NR, Hedron AJ. Dynamic behavior of rock masses. In: Zienkiewicz KCSaOC, editor. Rock mechanics and engineering practice. London: John Wiley \& Sons, Inc.; 1968. p. 203-27.

[41] Albert DG. Attenuation of outdoor sound propagation levels by a snow cover. vol. CRREL Report 93-20. Hanover, NH: USA CRREL; 1993.

[42] Carbee DL, Albert DG, Decato SN, Nagle JA. Barrier wall signal data II, SYDET Wall Experiment II. Hanover, $\mathrm{NH} ; 2001$.

[43] Perron Jr FE, Decato SN, Albert DG, Carbee DL. Blast absorber feasibility test short range measurements. Hanover, NH; 2007.

44] Decato SN, Albert DG, Perron Jr FE, Carbee DL. Short-range seismic and acoustic signature measurements through forest. Hanover, NH; 2005.

[45] Decato SN, Carbee DL, Albert DG, Nagle JA. XM153 Sympathetic Detonator (SYDET) acoustic signature measurements winter engineering test. Hanover, NH; 2003.

[46] Albert DG. Acoustic waveform inversion with application to seasonal snow covers. J Acoust Soc Am 2001;109:91-101.

47] ANSI. Estimating airblast characteristics for single point explosions in air, with a guide to evaluation of atmospheric propagation and effects. American National Standards Institute. vi+25; 1983.

[48] Vedy E, Eerden Fvd. Prediction of shock waves over a sound-absorbing area. Noise Control Eng J 2005;53:81-6.

[49] Vedy E, Eerden Fvd. Propagation of shock waves from source to receiver. Noise Control Eng J 2005;53:87-93.

[50] Biot MA. Theory of propagation of elastic waves in a fluid-saturated porous solid. I. Low-frequency range. J Acoust Soc Am 1956;28:168-78.

[51] Biot MA. Theory of propagation of elastic waves in a fluid-saturated porous solid. II. Higher frequency range. J Acoust Soc Am 1956;28:179-91.

[52] Biot MA. Mechanics of deformation and acoustic propagation in porous media. J Appl Phys 1962;33:1482-98.

[53] Biot MA. Generalized theory of acoustic propagation in porous dissipative media. J Acoust Soc Am 1962;34:1254-64

[54] Stoll RD. Theoretical aspects of sound transmission in sediments. J Acoust Soc Am 1980;68:1341-50

[55] Attenborough K. On the acoustic slow wave in air-filled granular media. J Acoust Soc Am 1987;81:93-102.

[56] Attenborough K. Ground parameter information for propagation modeling. J Acoust Soc Am 1992;92:418-27.

[57] Taherzadeh S. Sound propagation in inhomogeneous media, PhD Thesis in Engineering Mechanics. The Open University: Milton Keynes, UK; 1996. 